2017-02

Numerical analysis of the

thermomechanical behaviour of an integrally water-heated tool for composite manufacturing

\author{
Abdalrahman, $\mathrm{R}$ \\ http://hdl.handle.net/10026.1/12489
}

$10.1177 / 0731684416681502$

Journal of Reinforced Plastics and Composites

SAGE Publications

All content in PEARL is protected by copyright law. Author manuscripts are made available in accordance with publisher policies. Please cite only the published version using the details provided on the item record or document. In the absence of an open licence (e.g. Creative Commons), permissions for further reuse of content should be sought from the publisher or author. 


\title{
Numerical Analysis of the Thermomechanical Behavior of an Integrally Water-Heated Tool for Composite Manufacturing
}

\author{
Rzgar Abdalrahman $^{\mathrm{a} *}$, Stephen Grove ${ }^{\mathrm{b}}$, Adam Kyte $^{\mathrm{b}}$, Md Jahir Rizvi ${ }^{\mathrm{b}}$ \\ ${ }^{a}$ Mechanical Engineering Department, Polytechnic University of Slemani, Slemani, Iraq \\ ${ }^{\mathrm{b}}$ School of Marine Science \& Engineering, Plymouth University, Plymouth, UK PL4 8AA \\ *Corresponding Author: Rzgar M Abdalrahman: \\ rzgar.abdalrahman@plymouth.ac.uk
}

\begin{abstract}
Integrally water-heated tooling is one of the technologies available for 'out-ofautoclave' processing of advanced thermoset polymer composites. Temperature variation and temperature cycling, during heating and cooling, affect the properties of tool material and may produce undesirable thermal effects that degrade the tool durability and performance, especially when the tool construction involves various materials. Hence, in the current study, the performance and the thermomechanical behaviour of an integrally water-heated tool have been investigated using finite element analysis method. The intended tool, in the current study, consists different materials of composite and metals and is designed to heat up to $90^{\circ} \mathrm{C}$. Linear mechanical properties, CTEs and transient heating curve of each tool part are determined experimentally and set during the numerical analysis of tool structure to calculate the static thermal load effects of deformation, stress and strain. Comparing the numerical thermal effects with the ultimate stresses and strains of the tool materials concluded that no failure occurs with regard to static thermal loads. However, the calculated stresses are as much as the lowest magnitude of safety relates to the tool mould part made of Alepoxy.
\end{abstract}

Keywords: laminate and particle reinforced composites, strength, thermal properties, finite element analysis, deformation. 


\section{Introduction}

Composite tooling is subjected to thermal loading of heating and cooling during service, resulting in complex transient temperature variations through the tool, due to the combination of different material types and thermal properties. These temperature changes produce differential expansion or contraction. Thermal deformation will be stress-free in unrestrained isotropic materials, if the temperature variation is uniform over the body $[1,2]$. Generally, thermoelastic stresses occur in constrained anisotropic materials and could result in damage if they exceed allowable limits [3, 4]. When materials of different thermal expansions, e.g. bi-material strips and composite structures, are bonded together, temperature change causes internal thermal stresses and/or thermal deformation $[5,6]$.

Simple geometries can be modelled analytically. Timoshenko [7] obtained a model for the longitudinal normal stresses in bimetallic strips under thermal loading, based on elementary beam theory. Bi-material plates that are heated uniformly take a spherical form [7], because of the equal and constant curvatures that occur along the in-plane directions of the plate. Many researchers have used numerical methods to analyse bimaterial structures with different geometries and material properties. For example, Fovan [8] concluded that the maximum interfacial shear and normal stresses concentrate at the ends, through a distance roughly equal to the strip thickness. Suhair [9] considered the longitudinal and transverse interfacial compliances and suggested a somewhat complicated analytical model for evaluating the interfacial stresses in thermostat strips. The performance of Suhair's model is compared with two other models and emphases that extreme care must be taken when calculating the stresses near the free edges [10]. Timoshenko also proposed an analytic model for single tubes with different wall 
thickness ('thick', 'thin' and 'very thin') under thermal load [7, 11, 12]. The model calculates the steady state thermal stress, strain and deformation, assuming a radial temperature variation (across the tube wall thickness), constant axisymmetric temperature distribution and free expansion of the tube. Distribution of thermal stresses near the free ends of the tube is more complicated due to the discontinuity of the tube edge, and temperature variation along the tube thickness $[11,13]$.

Temperature variations modify and degrade mechanical and thermal properties of materials. In extreme cases the system performance and structural integrity may be affected $[14,15]$. Thermal-related failure may damage the structure directly (e.g. thermal deformation and thermal shock) or gradually. Thermal stress may initiate cracks, delaminations and thereby the system failure directly or gradually by creating incremental obstacles for the performances. The behaviour of composite materials is particularly complex, since mismatched thermal properties occur at the micro-scale (fibre/matrix) as well as at the laminate scale (ply) $[16,17]$.

Composites micro-mechanics deals with the mechanical properties of the constituents and their interaction, whereas macro-mechanics is concerned with the mechanical characteristics of the produced composite structure (laminate) without direct regard for the constituents and their interaction. The latter as followed in the current study. Compared to isotropic materials, there is a complicated relationship between the applied loads and deformation in anisotropic composites that can lead to unexpected behaviours. For example, temperature variation produces uniform expansion or contraction in all directions in isotropic materials, whereas it is non-uniform in composites and causes distortion. The expansivity mismatch between the different resins or adhesives in composite tooling, can cause disbonding of the heater from the 
tool and delamination of the bonded parts of the tool that affect tool thermal performances of heating and structure strength [18]. Shahidi [19] observed significant delaminations on composite tool skins, especially heated tools, that incorporated the use of steam and hot air heating pipes and deduced that the expected damage of the heater systems, especially the electro fabrics, may be eliminated by the placement of several insulation layers on the back-face of the tool. The most expected thermal damages in composites are transverse microcracks in the matrix, when the tensile strength of matrix is exceeded, delamination of the plies due to exceeding the interlaminar shear strength and fibre failure due to the buckling of fibres $[20,21]$.

The water-heated tool used in the present study involves different bonded materials (composites and metals) with different CTEs and performs heating up to $90^{\circ} \mathrm{C}$ suitable for curing of low temperature moulding (LTM) liquid resin or prepregs [22]. In this study, the tool structure is modelled in commercial finite element analysis software ANSYS to define the behaviour and distribution of the thermal stresses, strains and deformations caused by temperature variation through the tool geometry. This is preceded by validation studies on simple geometries with analytic solutions. The linear mechanical properties and CTEs of the constituent tool materials as well as the heating history (transient heating curve) of each tool part (tool surface, mould and channel) are characterised experimentally and set during the tool modelling. Finally the modelling results of tool thermomechanical behaviour are compared with the measured mechanical properties of the tool material to draw conclusions regarding the durability of the tool structure during repeated heating cycles. 


\section{Overview of the integrally water-heated tool}

The integrally water-heated tool (Figure 1) involves different parts (channel, tool surface, and mould) that are made of copper, CFRP (carbon non-crimp triaxial fibre and SR8100 epoxy) and Alepoxy (mixture of aluminium particles and epoxy), respectively [22]. The materials possess dissimilar thermal properties which result in different heating rates for each material. The tool is suitable for moulding a variety of composites with low temperature moulding (LTM) liquid resin or prepregs up to $90^{\circ} \mathrm{C}$ cure temperature. A number of K-type thermocouples were distributed at the tool interfaces between the mould, tool face and the channel as well as at the tool back face.

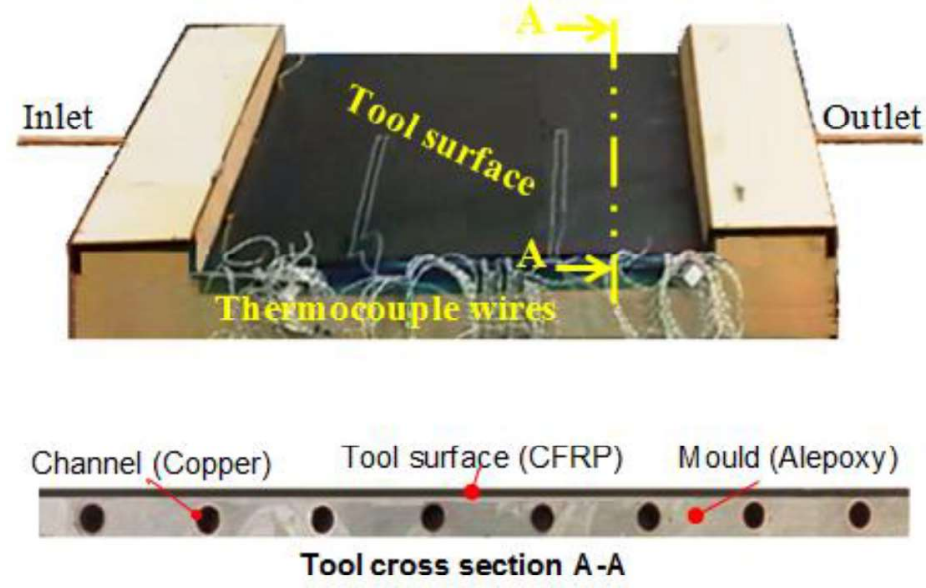

Figure 1 the water-heated tool.

\section{Numerical methodology}

\subsection{Numerical model of the tool geometry}

Using symmetry, one-quarter of the integrally water-heated tool, as shown in Figure 2, is modelled in ANSYS workbench. The symmetry faces are selected as frictionless supports, while the back face is selected to constraint the model displacement in $\mathrm{z}$ direction and prevent rigid body motion during analysis. 


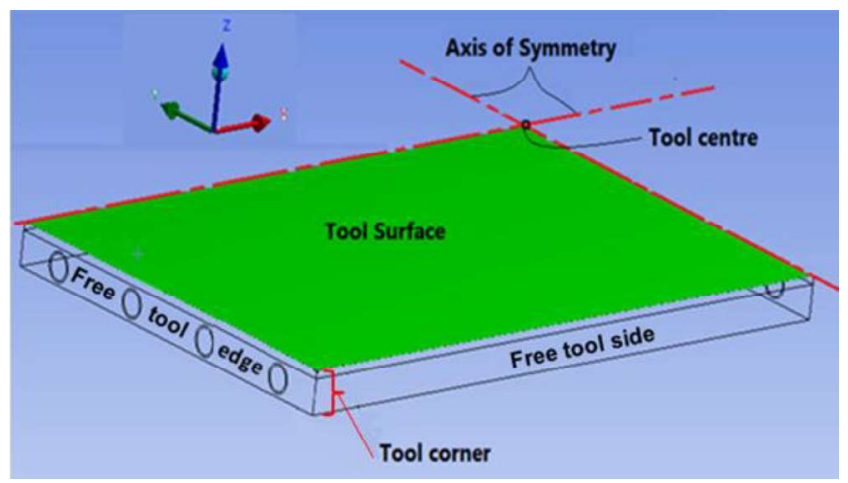

Figure 2 A one-quarter model of the tool

\subsection{Mesh generation}

Various meshing methods were applied and mesh quality was evaluated. A total of 47160 elements was used to provide accurate results with acceptable run time and PC memory requirement. Figure 3 shows part of the mesh used.

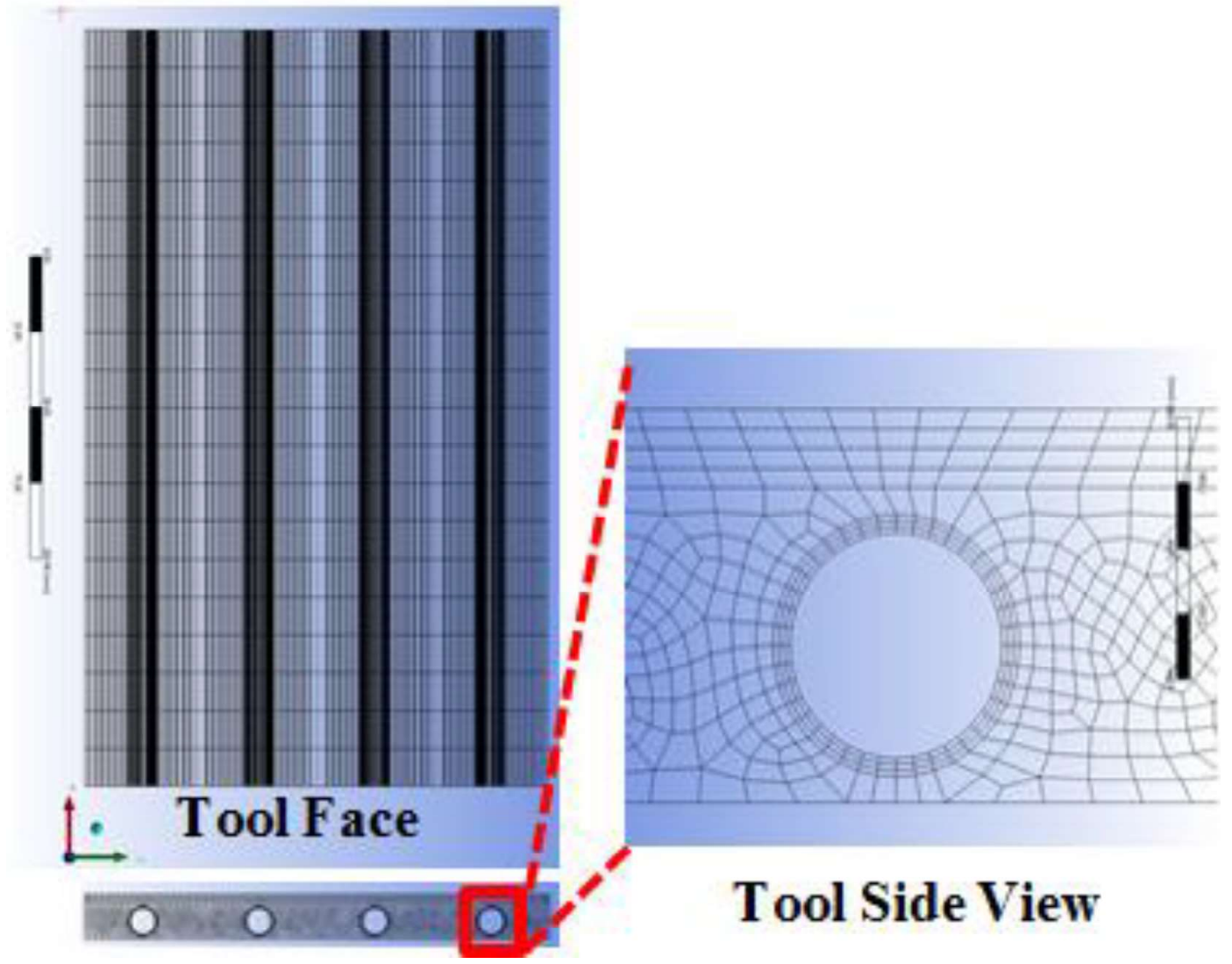

Figure 3 Meshing of the experimental tool model. 


\subsection{Applied boundary conditions}

The heating profile of each tool part, as plotted in Figure 5, was measured experimentally and set as boundary conditions for the simulation. The instantaneous temperature change of each tool part was measured experimentally by a number of thermocouples distributed at various points of the tool interfaces [22], and their average defines as the heating curve (Figure 4). Accordingly the fastest and the slowest heated parts, the channel (copper) and the tool face (CFRP), respectively, were identified and the maximum temperature variation between them was obtained as $15.6^{\circ} \mathrm{C}$. This occurs after about 400 s then reduces to $6.8^{\circ} \mathrm{C}$ (steady state) after about 800 s. Consequently the heating period of 700s was defined as the transient heating time $\left(H_{t}\right)$ for simulations.

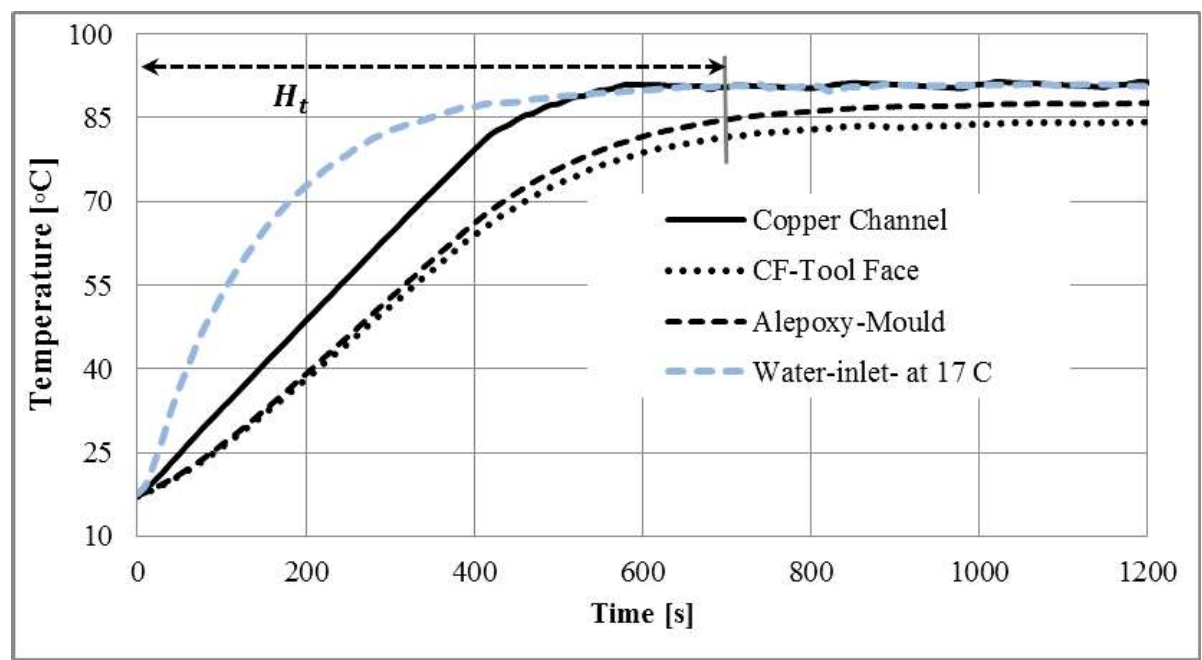

Figure 4 The heating profiles applied to each part of the tool model.

\subsection{Material properties}

In view of the small variation of tool material properties with temperature, and the limited temperature range operation, the model was run with constant thermal properties. 


\subsubsection{Mechanical properties}

The Alepoxy and CFRP laminate composites have isotropic and orthotropic properties, respectively. The constant linear mechanical properties, as listed in Table 1, are calculated from those of the constituents according to rules of mixture (RoM) and Autodesk software, respectively [23]. Figure 5 illustrates the calculation procedure for the CFRP laminate properties.

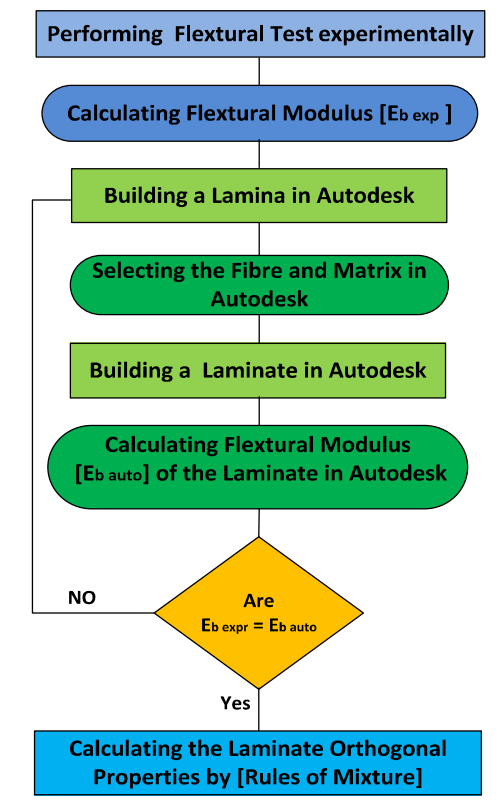

Figure 5 Calculation plan for the mechanical properties of CF laminate.

A flexural modulus test was performed on an Instron 3367 machine (using the threepoint bending method) in accordance with ASTM D790-07 [24], after preparing uniform rectangular specimens, at a span to depth ratio of 32 [25], according to the ISO 14125 [26], and flexural modulus of $44280 \mathrm{MPa}$ is obtained for the CFRP laminate. Different CFRP laminates of 0.53 volume fraction, $[45,0,-45,-45,90,45]_{\mathrm{s}}$ fibre orientations and $0.26 \mathrm{~mm}$ ply thickness, were built in Autodesk by laminas designed according to the matrices and carbon fibres available in the software. Autodesk defines the mechanical properties of each laminate constructed including flexural modulus, 
which was compared with the experimental value to find the one most similar. Accordingly the desired linear mechanical properties of the actual CFRP laminate (Table 1) are obtained.

\subsubsection{Coefficient of thermal expansion (CTE)}

The coefficient of thermal expansion (CTE) of the tool materials, as listed in Table 1, were measured in accordance to ASTM D5335-14 [27] utilizing the electrical resistance strain gauge technique. The method determines the CTE of the test materials by comparing with that of a reference material with a known expansion [28, 29]. Linear strain gauges of SGD-10 type, $1000 \Omega$ resistance, 2.13 gauge factor and $\pm 0.235 \%$ tolerance, and K-type thermocouples were used. The thermocouple has measuring ability ranges between $0^{\circ} \mathrm{C}$ to $200^{\circ} \mathrm{C}, \pm 2.5^{\circ} \mathrm{C}$ tolerance and made by Labfacility according to IEC 584-2 specification, formerly BS4937:1983.

Table 1 Linear mechanical and thermal properties of the tool materials

\begin{tabular}{|c|c|c|c|c|c|c|c|c|c|}
\hline \multicolumn{2}{|c|}{ Materials } & $\begin{array}{l}\text { Fibre } \\
\text { Volume } \\
\text { fraction }\end{array}$ & $\begin{array}{l}\text { Poisson's } \\
\text { ratio }\end{array}$ & CTE & $\begin{array}{c}\text { tensile } \\
\text { modulus }\end{array}$ & $\begin{array}{c}\text { Shear } \\
\text { modulus }\end{array}$ & $\begin{array}{c}\text { Ultimate } \\
\text { tensile } \\
\text { strength }\end{array}$ & $\begin{array}{l}\text { Ultimate } \\
\text { compressive } \\
\text { strength }\end{array}$ & $\begin{array}{l}\text { Ultimate } \\
\text { Shear } \\
\text { strength }\end{array}$ \\
\hline & & - & - & ${ }^{\circ} \mathrm{C}^{-1}$ & $\mathrm{MPa}$ & $\mathrm{MPa}$ & $\mathrm{MPa}$ & $\mathrm{MPa}$ & $\mathrm{MPa}$ \\
\hline Alepoxy & orthotropic & 0.48 & 0.34 & $32 \times 10^{-6}$ & 6200 & 2300 & 120 & -190 & 140 \\
\hline Copper $^{[30]}$ & orthotropic & - & 0.34 & $17 \times 10^{-6}$ & $110 \times 10^{3}$ & $41 \times 10^{3}$ & 430 & -430 & 170 \\
\hline \multirow{2}{*}{ CFRP } & In-plane & 0.58 & 0.451 & $1.9 \times 10^{-6}$ & 8100 & $21 \times 10^{3}$ & 740 & -490 & 53 \\
\hline & Out-plane & 0.58 & 0.219 & $2.3 \times 10^{-6}$ & 35600 & 2800 & 160 & -240 & 50 \\
\hline
\end{tabular}

The measurement showed the orthogonal in-plane CTEs of Alepoxy to be quite similar, but there is a difference of about $\pm 0.1 \times 10^{-6}{ }^{\circ} \mathrm{C}^{-1}$ in that of CFRP, therefore an average of $1.9 \times 10^{-6}{ }^{\circ} \mathrm{C}^{-1}$ was used. The through-thickness CTE of Alepoxy is assumed to be the same as in-plane due to its isotropic behaviour, but that of the orthotropic CFRP laminate is calculated by the RoM, according to its in-plane CTE and that of the fibre 
constituent $\left(1.2 \times 10^{-6}{ }^{\circ} \mathrm{C}^{-1}\right)$, because the laminate thickness is too small for direct measurement.

\section{Verification of numerical methodology}

A simple analytical model of a hollow cylinder was used to validate the correct assignment of boundary conditions and material properties. The tool channel has a circular profile and transfers hot water $\left(\right.$ at $90{ }^{\circ} \mathrm{C}$ ) to heat the tool from ambient temperature $\left(17^{\circ} \mathrm{C}\right)$, and is therefore subjected to thermal stresses and deformation. Therefore a copper tube of $60 \mathrm{~mm}$ length, $5 \mathrm{~mm}$ external diameter and $0.7 \mathrm{~mm}$ wall thickness, was used as a validation model. The temperatures of the internal and external surfaces of the tube were set as that of water and ambient, resulting in a temperature variation of $73^{\circ} \mathrm{C}$ through the wall thickness (Figure 6).

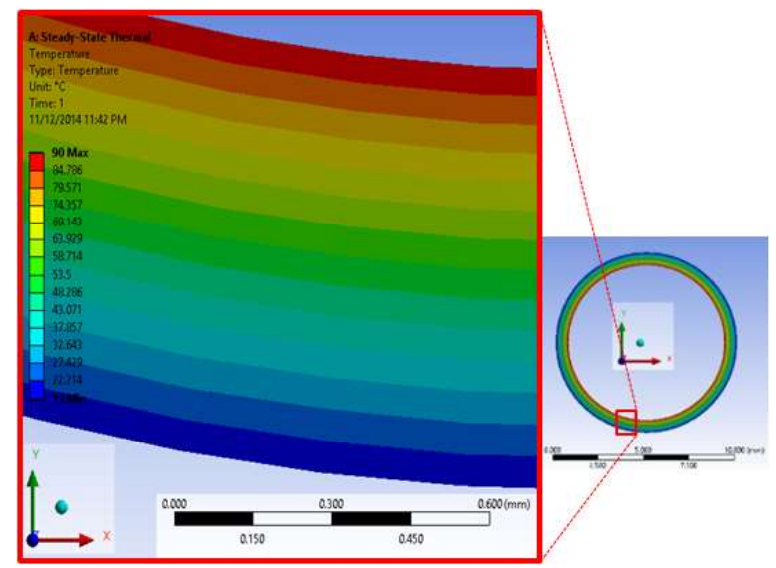

Figure 6 Numerical distribution of temperature throughout the tube thickness. The internal and external faces of the tube were set at $90{ }^{\circ} \mathrm{C}$ and $17^{\circ} \mathrm{C}$, respectively as boundary condition.

Timoshenko's mathematical model [12] for thin wall hollow cylinders is applied to calculate the bending moment at the free ends of the model and consequently the maximum amounts of tube deformation, strain and stress (longitudinal and tangential). Although the model is axisymmetric, its 3D geometry is analysed to offer the best understanding of the structural 
behaviour, using symmetry. A half-length of the tube is modelled in ANSYS Workbench. Figure 7 illustrates a simulation result.

Maximum analytical and numerical deformations, stresses and strains, are listed in Table 2 and very good agreement was obtained, confirming the correct assignment of the boundary conditions and the material properties during the numerical analysis. Results indicated that the

\begin{tabular}{lccc} 
& Max. deformation & Max. strain & Axial \& tangential stresses \\
\cline { 2 - 4 } Analysis methods & $\mathrm{mm}$ & $\mathrm{mm} / \mathrm{mm}$ & $\mathrm{MPa}$ \\
\hline Analytic & $2.96 \times 10^{-3}$ & $5.82 \times 10^{-4}$ & -109.03 to 97.8 \\
Numerical & $3 \times 10^{-3}$ & $5.9 \times 10^{-4}$ & -107.85 to 98.7 \\
Absolute difference percentage & $1.3 \%$ & $1.4 \%$ & $1.3 \%$
\end{tabular}

about one twelfth of the total tube length) as illustrated in Figures 8 to 10, due to temperature variation and the bending moments generated at the tube free edges.

Table 2 The analytic and numerical analysis results of the cylindrical model

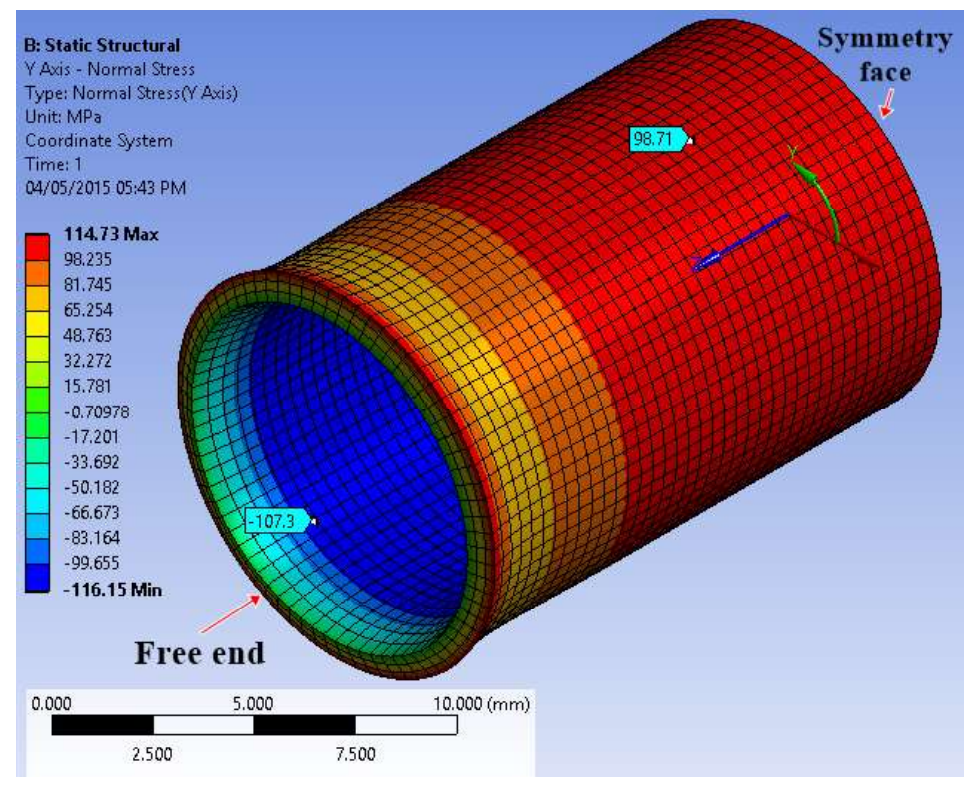

Figure 7 Tangential normal stresses in the cylindrical model 


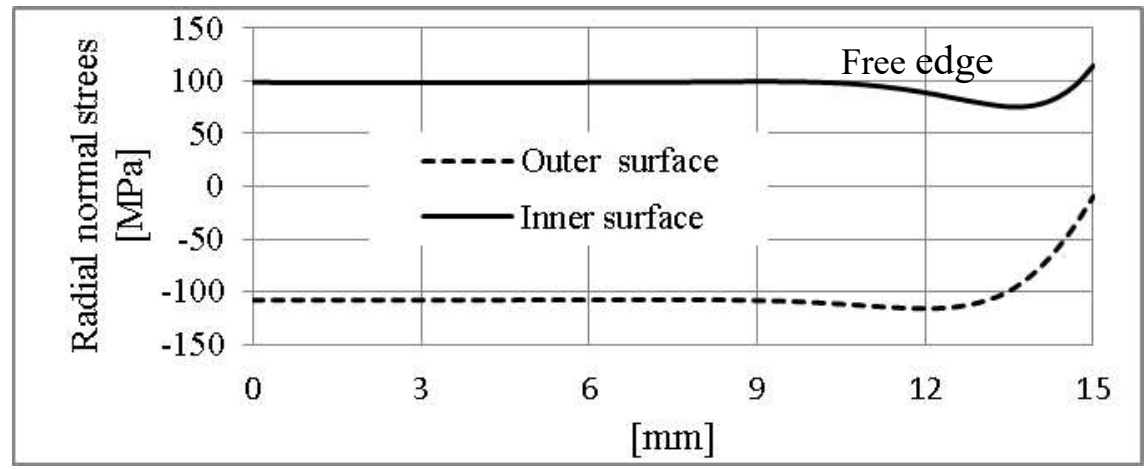

Figure 8 Tangential normal stress along the inner and outer tube surfaces, towards the free end.

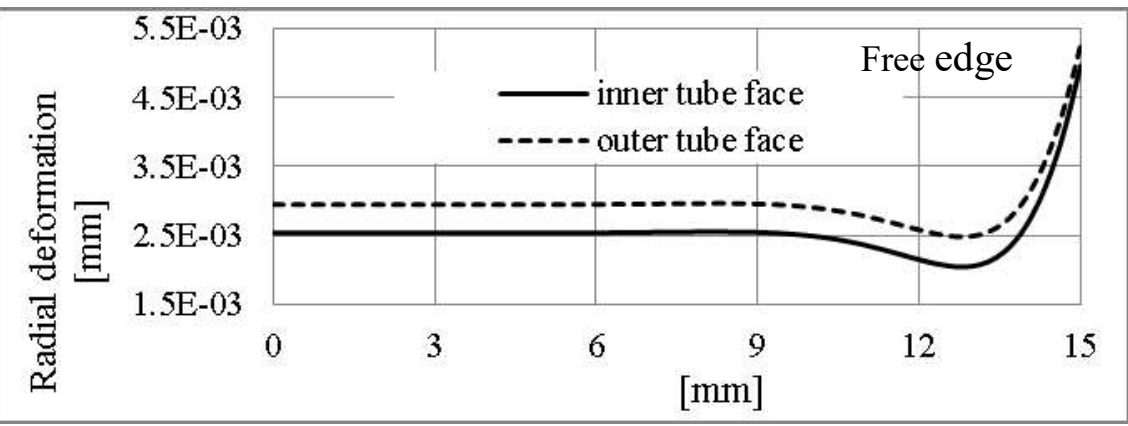

Figure 9 Radial deformation along the length of inner and outer tube surfaces, towards the free end.

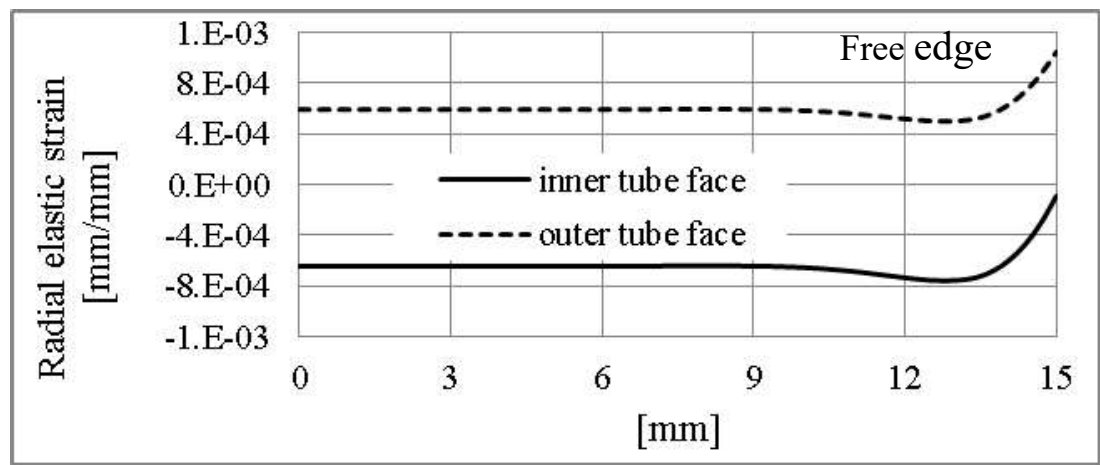

Figure 10 Radial elastic strain along the length of inner and outer tube surfaces, towards the free end.

\section{Numerical results and discussions}

\subsection{Total deformations}

The transient total deformation (the vector sum all directional displacements) of the tool is plotted in Figure 11. It increases almost linearly until about 400s, then gradually until it reaches steady state at about 700s. This behaviour of tool deformation is directly 
related to the applied boundary conditions (Section 3.3). Maximum total deformation of the tool is $0.23 \mathrm{~mm}$ at the free ends (near the corners) as shown in Figure 12A, which also shows the tool bending towards the tool surface near the free edges, sides and especially the corners due to the lower CTE of CFRP compared to Alepoxy. Figure 12B illustrates that the total deformation at the tool symmetry faces is lower, and does not exceed $0.107 \mathrm{~mm}$. The high deformation of the tool near the free edges is due to the free ends of the copper channels and reaches $0.23 \mathrm{~mm}$, as illustrated in Figure 13, while it does not exceed $0.18 \mathrm{~mm}$ in the rest of the channel.

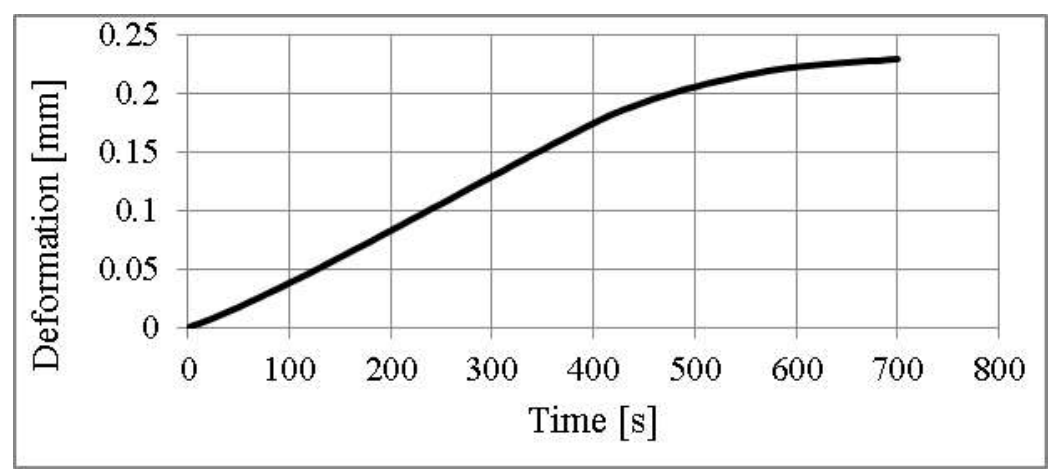

Figure 11 Transient total deformation in the tool. 

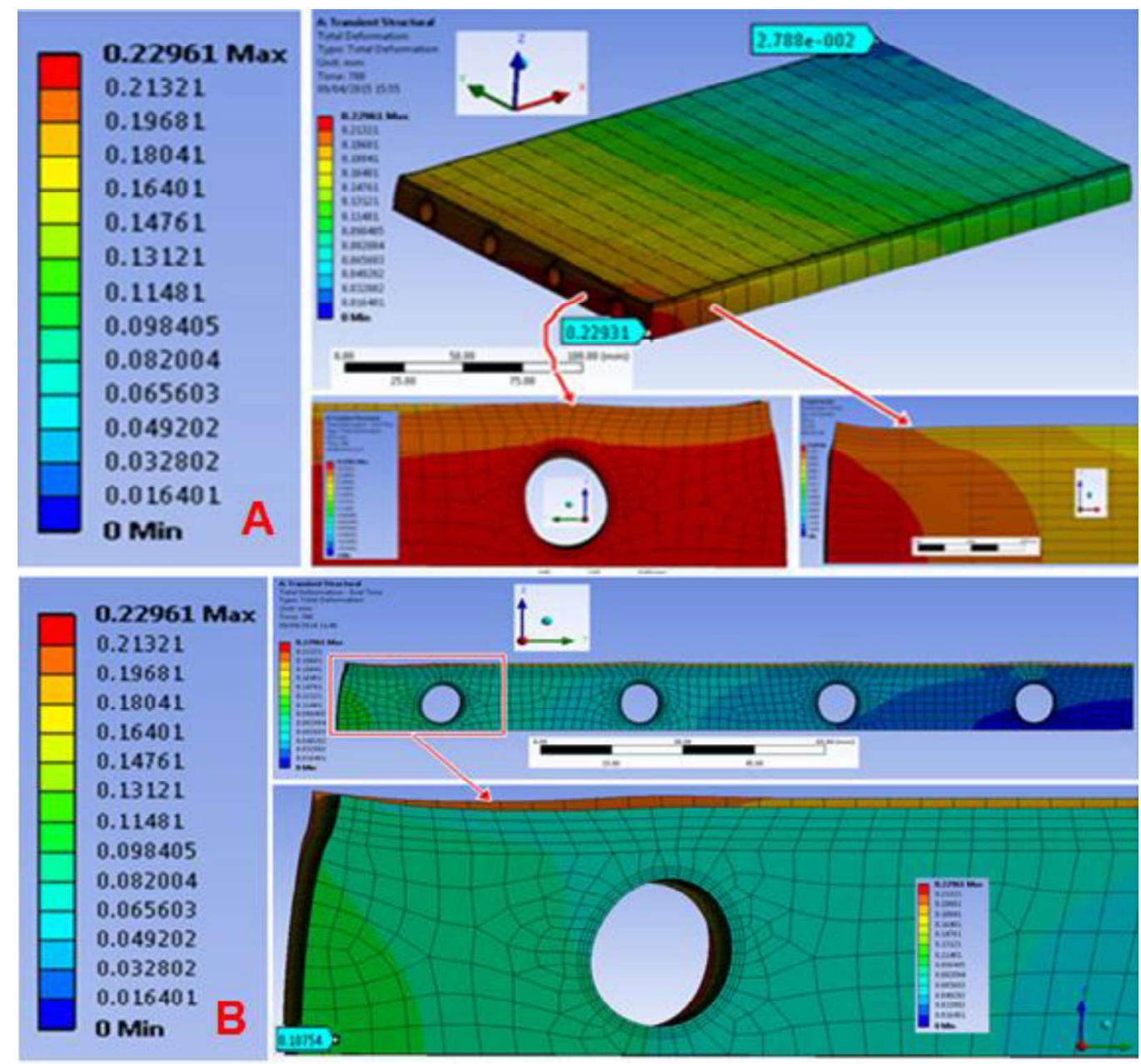

Figure 12 Total deformation in the: A) tool model and its free edge. B) Transverse symmetry side of the tool, $H_{t}=700 \mathrm{~s}$
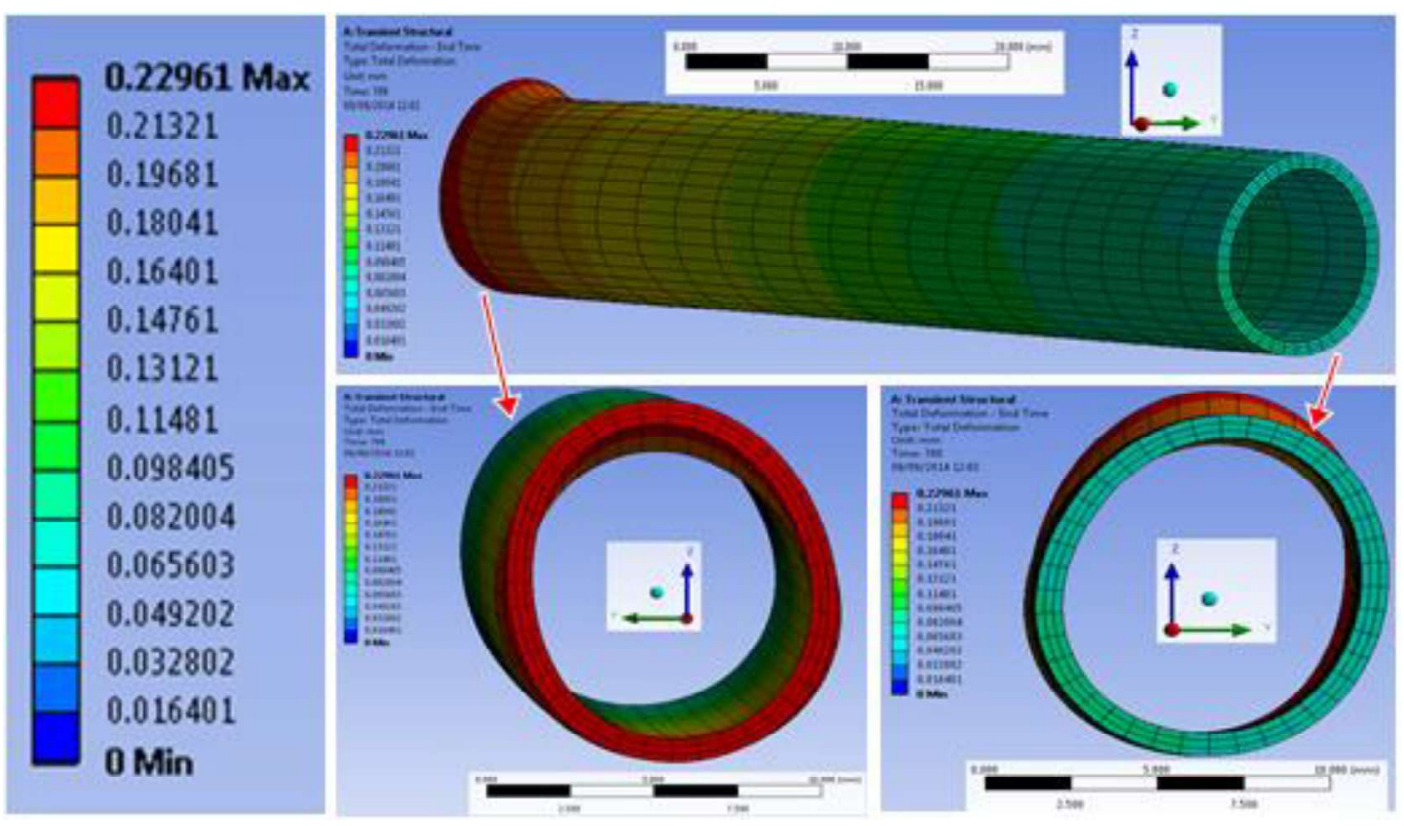
Figure 13 Total deformation in a channel, $H_{t}=700 \mathrm{~s}$

\subsection{Directional deformation}

The maximum deformation along each of the tool free corners, edges and sides, occurs in the longitudinal (x-axis) direction and reaches $0.21 \mathrm{~mm}$. Figure 14 illustrates that along the tool free corners, in which the maximum deformation occurs in the Alepoxy part (mould).

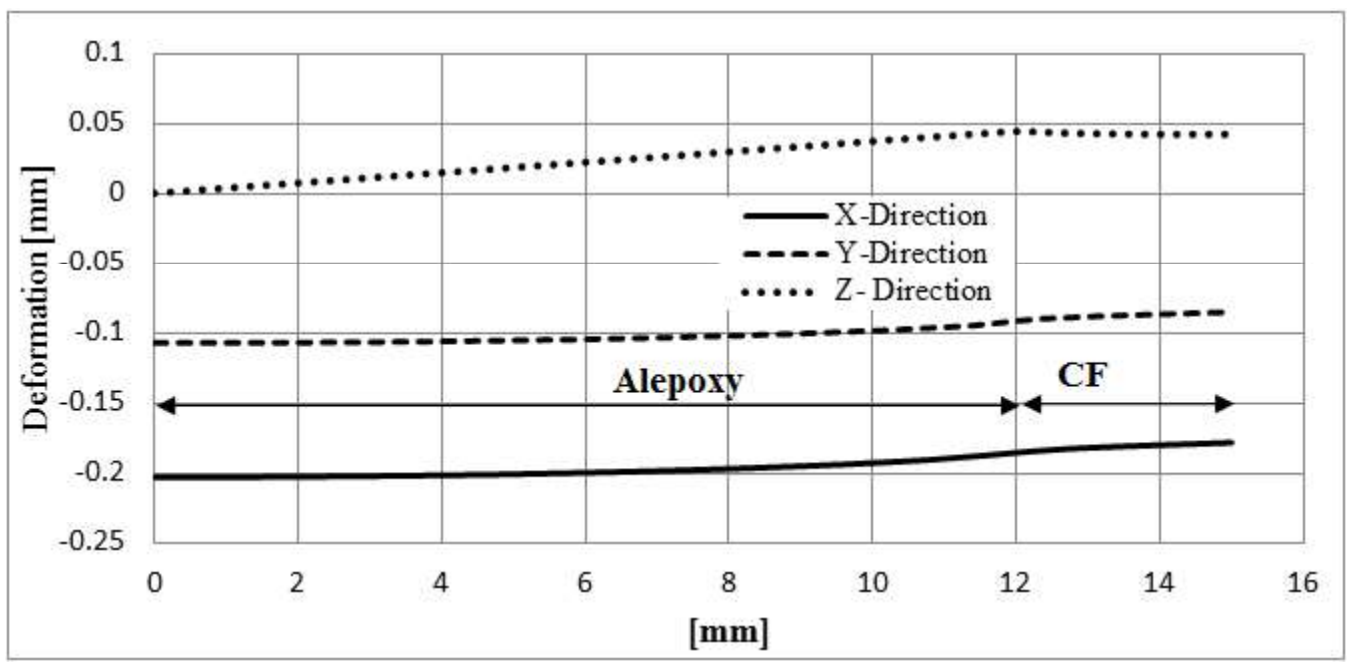

Figure 14 Directional deformations along the tool corners, $H_{t}=700 \mathrm{~s}$

\subsection{Normal (tensile and compressive) elastic strain}

Figures 15 and 16 illustrate that the highest longitudinal (x-axis) normal elastic strain (-

$1.2 \times 10^{-3}$ ) occurs only near the free edges of the tool interface between Alepoxy and CFRP, while in the rest of the tool body is equal to or lower than $-7.8 \times 10^{-4} \mathrm{~mm} / \mathrm{mm}$. The tool face is in tension, while other parts are under compression due to the difference of their expansivity. 


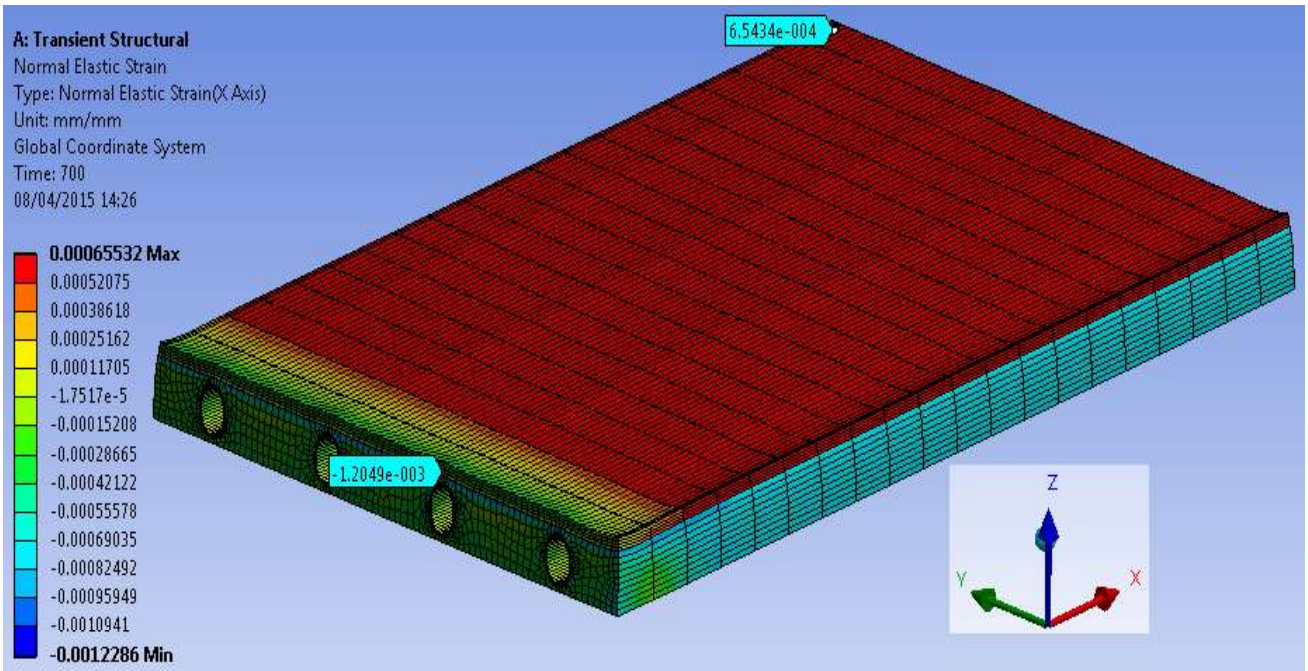

Figure 15 Longitudinal (x-axis) normal elastic strain in the tool, $H_{t}=700 \mathrm{~s}$

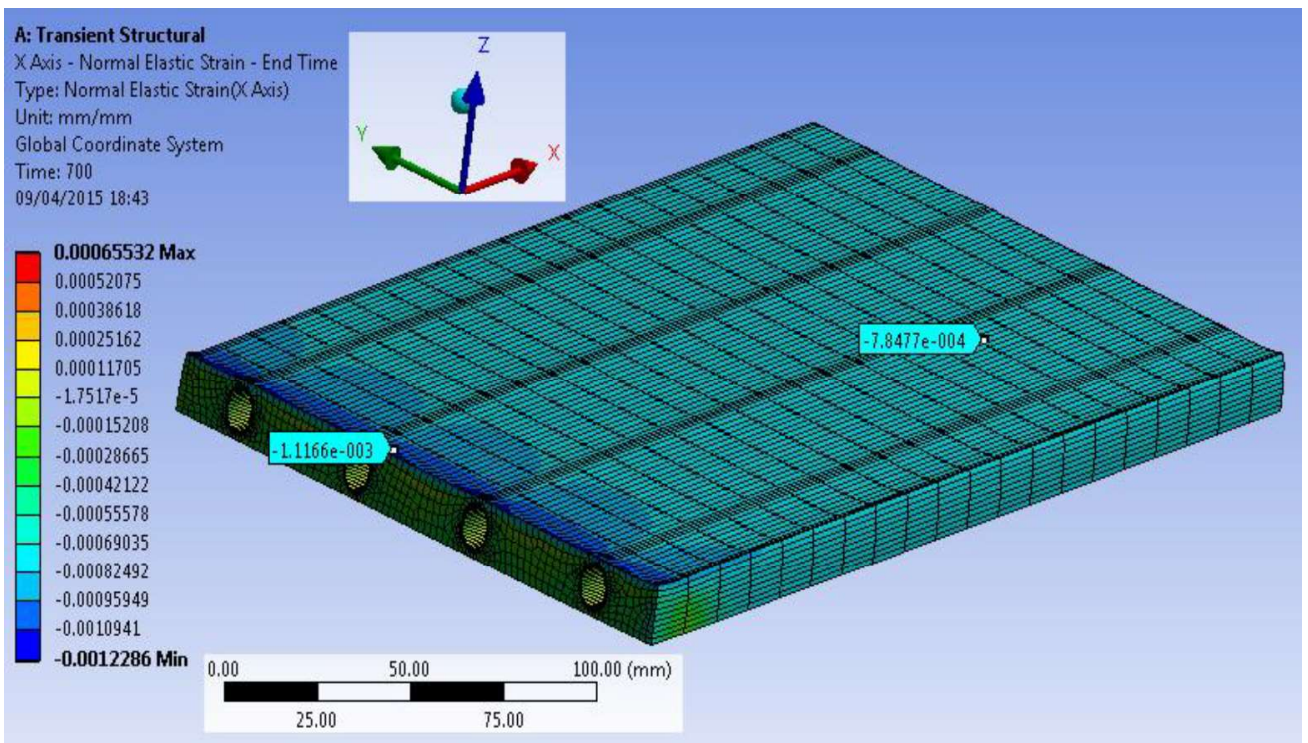

Figure 16 Longitudinal (x-axis) normal elastic strain in the mould, $H_{t}=700 \mathrm{~s}$

\subsection{Normal (tensile and compressive) stresses}

The transient longitudinal (x-axis) normal (tension and compression) stresses are plotted in Figure 17, which illustrates an almost linear increase until about 400s then slowing down until reaches the steady state after about 700s of heating. Figure 18 illustrates that the maximum tensile stress of $41.4 \mathrm{MPa}$ occurs in the CFRP tool face (due to its low 
CTE) while the maximum compressive stress of -102.4 MPa occurs at the internal face of the high dilatable channels (Figure 19). Both reduce near the free edges, corners and sides.

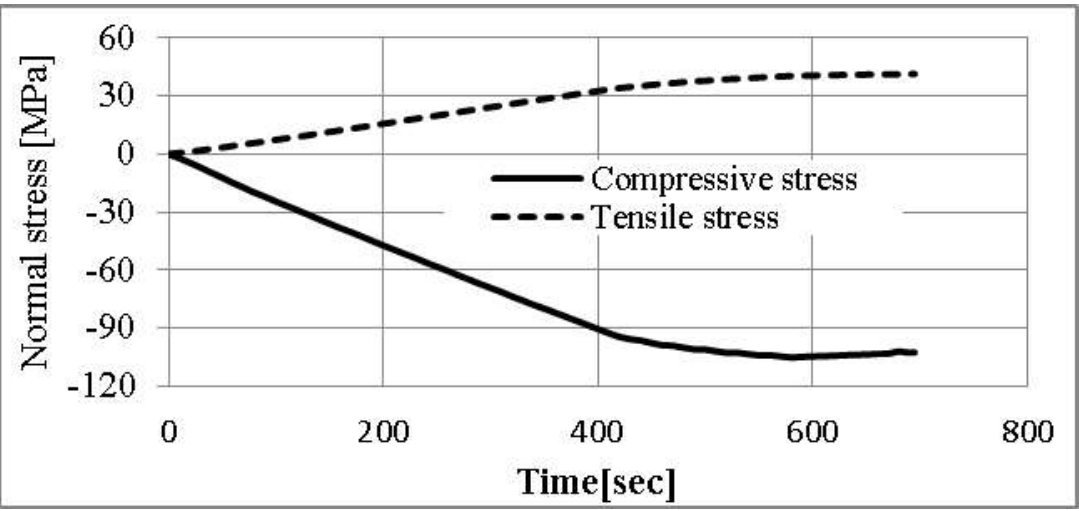

Figure 17 Longitudinal (x-axis) normal stresses in the tool

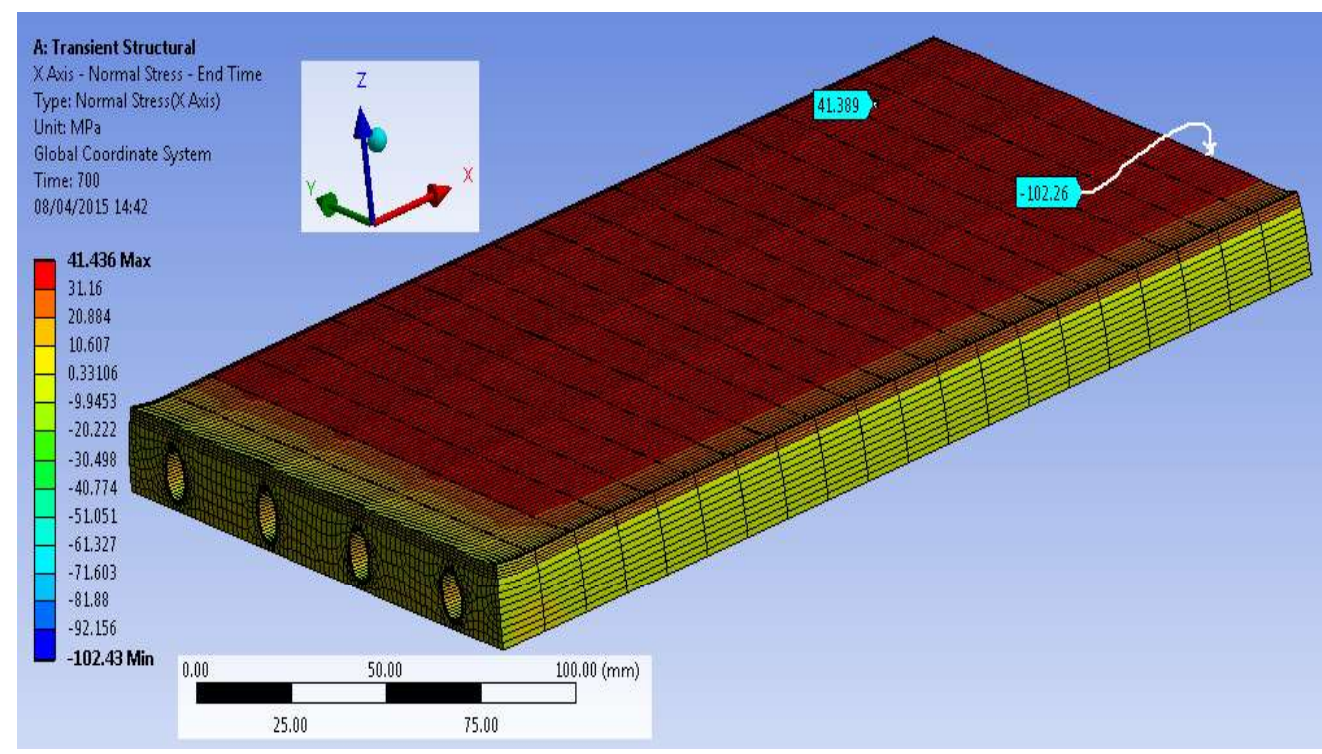

Figure 18 Longitudinal (x-axis) normal stress in the tool, $H_{t}=700 \mathrm{~s}$ 


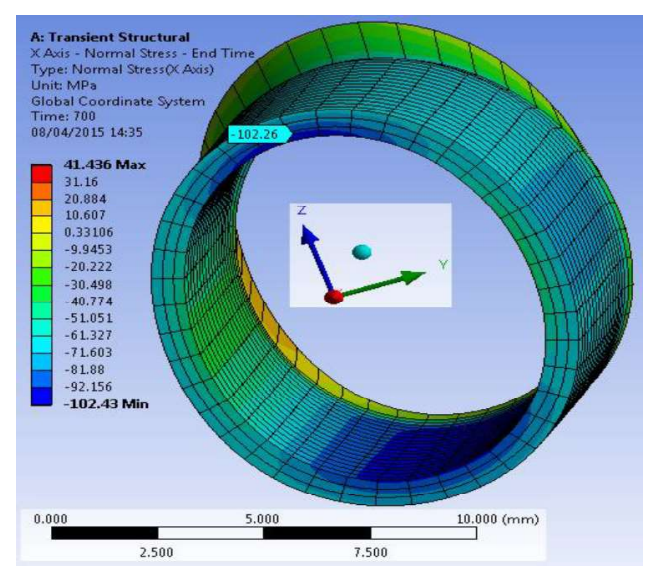

Figure 19 Longitudinal (x-axis) normal stress in a channel, $H_{t}=700 \mathrm{~s}$

The maximum normal stress, along the transverse and longitudinal symmetry sides of the tool interface between CFRP and Alepoxy (Figure 20) is $38.8 \mathrm{MPa}$ and occurs in the longitudinal (x-direction), especially over the channels in the transverse symmetry side. Normal stress along the tool corners, as shown in Figure 21, changes intricately at the interface between the CFRP and Alepoxy, reaching a maximum value of about $15 \mathrm{MPa}$ in the x-direction. Complex changes also occur to the normal stress along the channel free edges, as shown in Figure 22, and its maximum value of $15 \mathrm{MPa}$ occurs in the radial direction. This is because of overlapping the bending moments generated at the free edges of the bonded materials (Alepoxy, CFRP and copper) as a result of the expansion restriction between them.

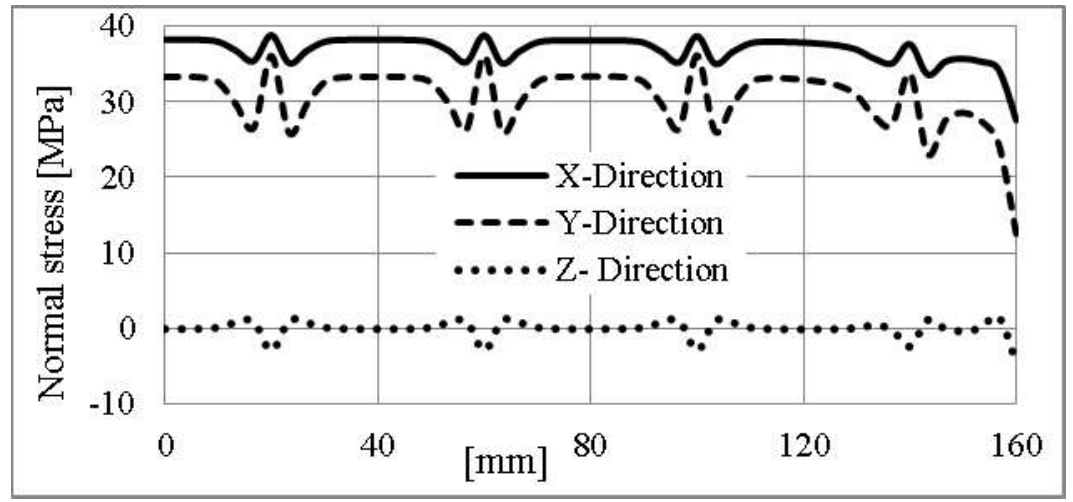

Figure 20 Normal stress along the transverse symmetry side of the tool interface between CFRP and Alepoxy 


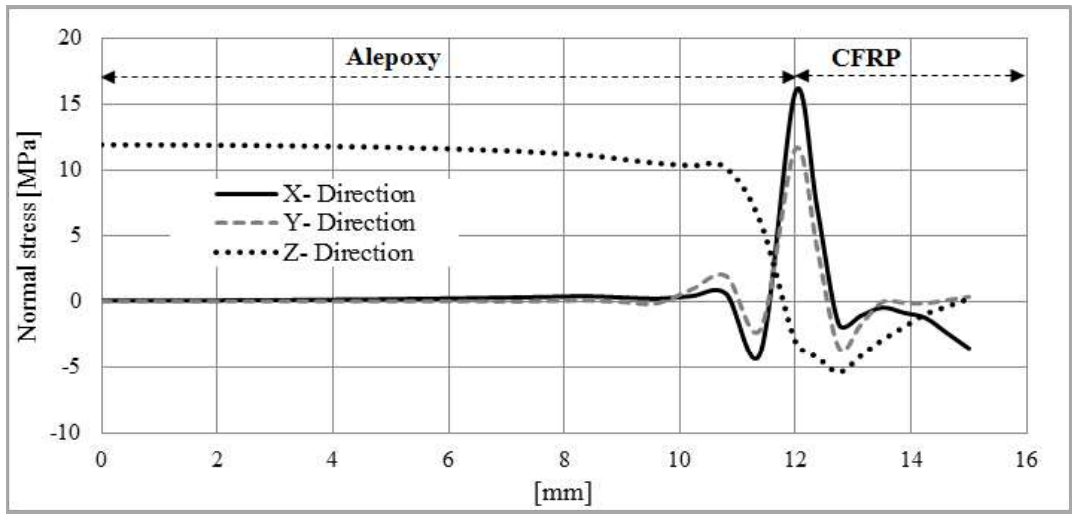

Figure 21 Normal stress along the tool corners

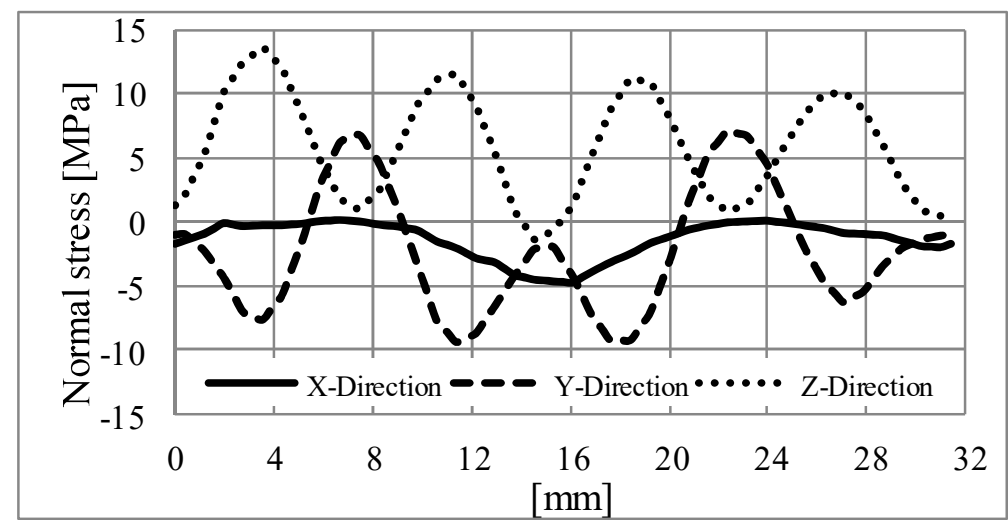

Figure 22 Normal stress along the channel free ends

\subsection{In-plane shear stress}

Figure 23A shows that the total xy-plane shear stress (at the interfaces between the tool face, mould and channels) generally does not exceed $0.1 \mathrm{MPa}$, but amounts of $\pm 24 \mathrm{MPa}$ occur just near the free ends of channel, as shown in Figure 23B. The maximum inplane shear along the transverse free edges of the interface between the Alepoxy and CFRP, as illustrated in Figures 24 , is $8.6 \mathrm{MPa}$ in the xz-plane, particularly over the channels. This is due to the intricate change of shear stress along the free edges of the interface between the channel and Alepoxy, as shown in Figure 25, which reaches the maximum value of $7.8 \mathrm{MPa}$ in yz-plane. 


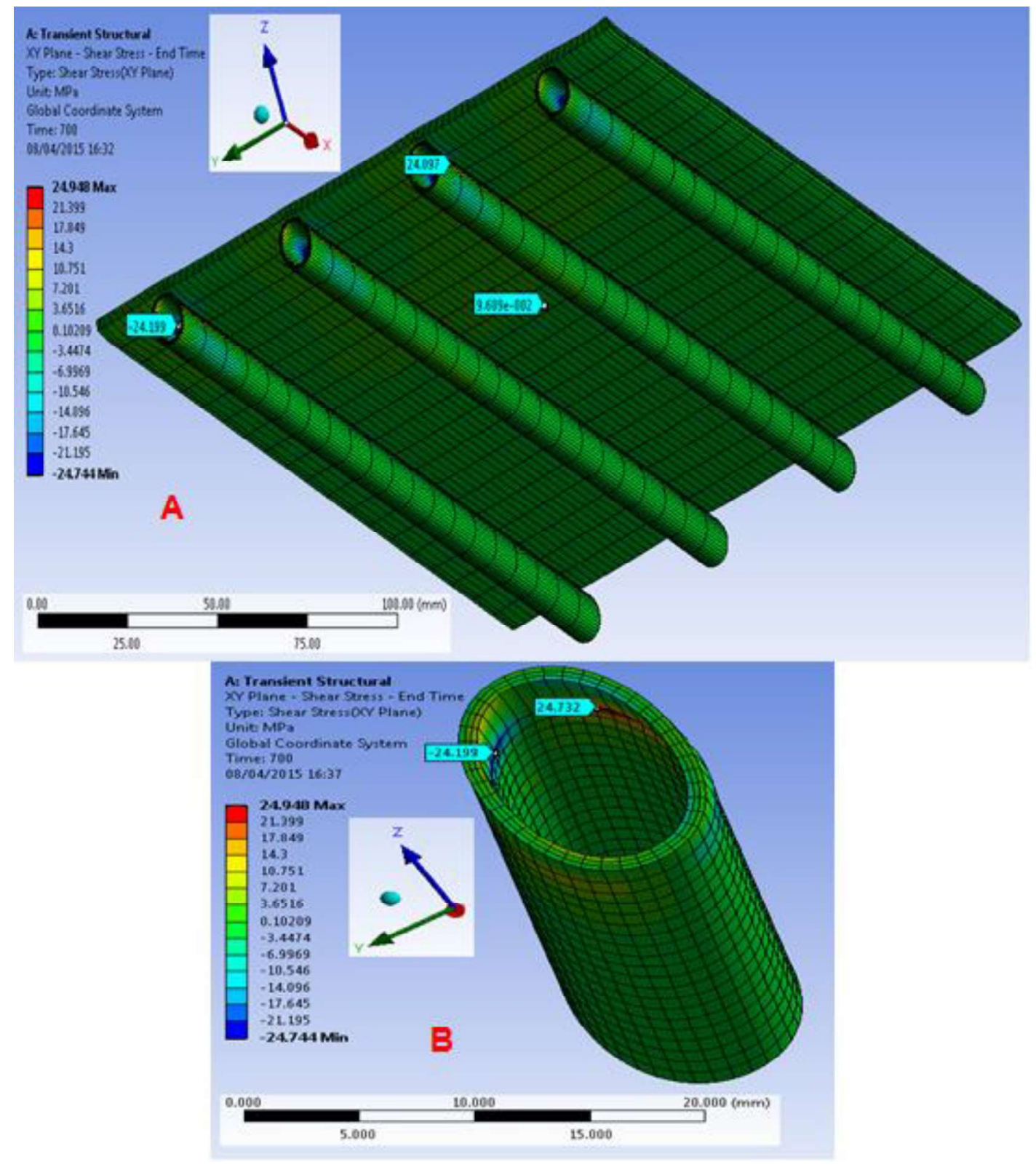

Figure 23 xy-plane shear stresses: A) at the tool interfaces. B) in the channel, $H_{t}=700 \mathrm{~s}$

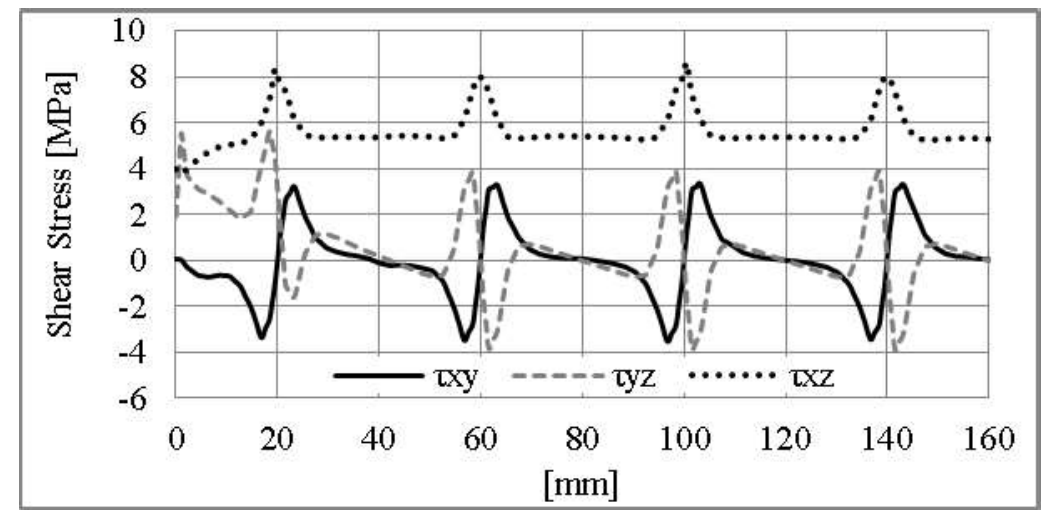

Figure 24 Plane shear stresses along free ends of the Alepoxy and CFRP interface. 


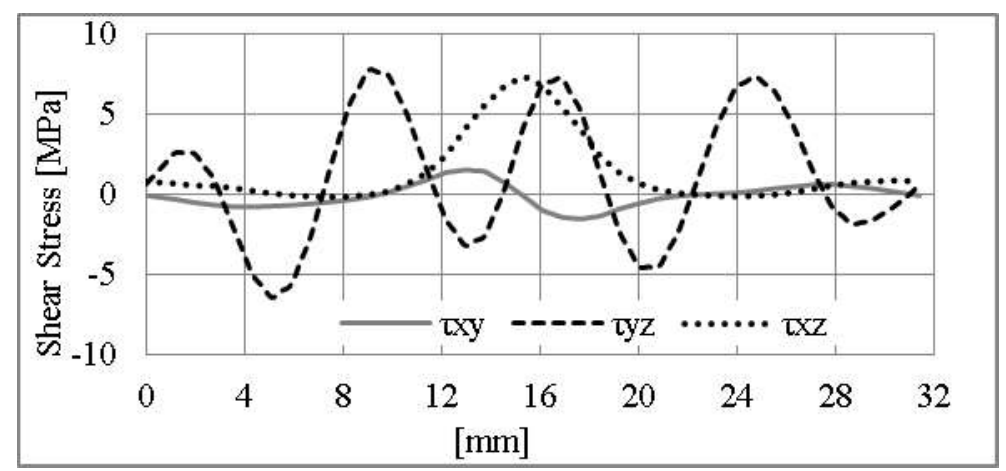

Figure 25 Plane shear stresses along the tube free ends (mould channel interface).

\section{Conclusion}

Numerical results show that:

- The thermal deformation and normal (tension and compression) stresses, in the heated tool, have the same trend as the temperature variation between the tool parts, which increases linearly at the beginning of heating until about 400s, and then slows down until steady state at about 700 s.

- The highest thermal stresses occur in the tool body due to the expansion restriction between the bonded parts, while the highest deformation occurs near the free edges, corners and sides of the tool due to the local irregularities and the overlapping bending moments.

- The maximum values of normal stresses, in-plane shear, normal elastic strain and deformation occur on the internal face of the high dilatable copper channel, the free edges of the tool and its parts, reaching about $-102 \mathrm{MPa}, 24 \mathrm{MPa},-1.2 \times 10^{-3} \mathrm{~mm} / \mathrm{mm}$ and $0.23 \mathrm{~mm}$, respectively.

- Magnitudes of the static normal stresses, in-plane shear, normal elastic strain and deformation anywhere in the tool body, except the locations illustrated previously, does not exceed $41.4 \mathrm{MPa}, 0.1 \mathrm{MPa}, 7.8 \times 10^{-4} \mathrm{~mm} / \mathrm{mm}$ and $0.18 \mathrm{~mm}$, respectively.

- Comparing these results with ultimate stresses and strains (calculated from the ultimate stresses and module) listed in Table 1, it can be seen that the lowest magnitude of safety relates to mould part made of Alepoxy, while it may be concluded that no failure occurs with regard to static thermal loads. The calculated 
stresses are significant fractions of the allowable, so the question of the effect of repeated temperature cycling remains unanswered, and is an important topic for future investigation.

\section{Acknowledgements}

The authors would like to acknowledge financial support from the Ministry of Higher

Education and Scientific Research of the Republic of Iraq. Particular thanks are given to Polytechnic University of Slemani and the University of Plymouth for their support. Dr Richard Cullen, Terry Richards, Kev Solman and Andy Arnold (all Plymouth University) assisted with various aspects of the experimental work.

\section{References}

1. $\quad$ Askeland, D.R., et al., The Science and Engineering of Materials 6th ed. 2011: Stamford, Conn. : Cengage Learning.

2. $\quad$ Rogin, M., The Basics of Pipe Thermal Expansion. 2010: Pumps \& Systems.

3. Herakovich, C.T. and M.W. Hyer, Damage-induced property changes in composites subjected to cyclic thermal loading. Engineering Fracture Mechanics, 1986. 25(5-6): p. 779-791.

4. Carden, A.E., Thermal Fatigue- an Analysis of the Experimental Method. 1963, Oak Ridge National Laboratory-U.S. Atomic Energy Commision: USA.

5. Chen, W. and C. Nelson, Thermal stress in bonded joints. IBM Journal of Research and Development, 1979. 23(2): p. 179-188.

6. Bruno, A.B. and J.H. Weiner, Theory of Thermal Stresses 2011, USA: Dover Publications Inc. 608 pages

7. Timoshenko, S., Analysis of Bi-metal Thermostats. Journal of the Optical Society of America, 1925. 11(3): p. 233-255.

8. Fo-van, C., Thermal contact stresses of bi-metal strip thermostat. Applied Mathematics and Mechanics, 1983. 4(3): p. 363-376.

9. Suhir, E., Interfacial stresses in bimetal thermostats. Journal of Applied mechanics, 1989. 56(3): p. 595-600.

10. Eischen, J.W., C. Chung, and J.H. Kim, Realistic Modeling of Edge Effect Stresses in Bimaterial Elements. Journal of Electronic Packaging, 1990. 112(1): p. 16-23.

11. Timoshenko, S. and J.N. Goodier, Theory of Elasticity. 2nd ed. 1951: McGrawHill

12. Timoshenko, S., Strength of Materials. 3rd ed. 1956, New Jersey: D.Van Nostrand Company,Inc. 
13. Irfan, M.A. and W. Chapman, Thermal stresses in radiant tubes due to axial, circumferential and radial temperature distributions. Applied Thermal Engineering, 2009. 29(10): p. 1913-1920.

14. Crompton, T.R., Thermal Methods of Polymer Analysis 2013: Rapra Technology Ltd.

15. Jones, J.C., The Principles of Thermal Sciences and Their Application to Engineering. 2000: Whittles Publishing.

16. Hancox, N.L., Thermal effects on polymer matrix composites: Part 1. Thermal cycling. Materials \& Design, 1998. 19(3): p. 85-91.

17. Kamiya, N., Bimodulus Thermoelasticity Considering Temperature-Dependent Material Properties. Mechanics of Bimodulus Materials, 1979. 33,: p. 29-37.

18. Progoulakis, I., Heated tooling for aerospace composites manufacture, in Faculty of Science and Technology. 2004, University of Plymouth: UK. p. 301.

19. Shahidi, E. Composite tooling solutions for new manufacturing. in Proceedings of the 1st Stade Composite Colloquium Techniques. 2000. Stade, Germany.

20. Cohen, D., M.W. Hyer, and S.S. Tompkins, The effects of thermal cycling on matrix cracking and stiffness changes in composite tubes, in 16th SAMPE Technical Conference 1984: Albuquerque, New Mexico. p. 577-588.

21. Tompkins, S. and S.L. Williams, Effects of thermal cycling on mechanical properties of graphite polyimide. Journal of Spacecraft and Rockets, 1984. 21(3): p. 274-280.

22. Abdalrahman, R., et al., Numerical Simulation and Experimental Verification of Heating Performance of an Integrally Water-heated Tool. Journal of Reinforced Plastics and Composites, 2016(8).

23. Autodesk, Simulation Composite Design User's Guide. 2013.

24. AST D790-07, Standard Test Methods for Flextural Properties of Unreinforced and Reinforced Plastics and Electrical Insulating Materials. 2007. 8.01

25. Petrescu, I., C. Mohora, and C. Ispas, The Determination of Young Modulus For CFRP Using Three Point Bending Test at Different Span Lengths. Journal Scientific Bulletin Series D, 2013. 75(1): p. 121-128.

26. ISO 14125, Fibre-reinforced plastic composites-determination of flexural properties. 1998, European Committee for Standardization.

27. ASTM D5335-14, Standard Test Method for Linear Coefficient of Thermal Expansion of Rock Using Bonded Electric Resistance Strain Gauges. ASTM International, West Conshohocken, Book of Standards, 2014. 4.08(PA).

28. IPC, IPC-TM-650 Test Methods Manual. 2000: Association Connecting Electronics Industries.

29. Scalea, F.L.d., Measurement of thermal expansion coefficients of composites using strain gages. Experimental Mechanics, 1998. 38(4): p. 233-241.

30. Davis, J.R., Copper and copper alloys. 2001: Materials Park, OH : ASM International 
Table 1 Linear mechanical and thermal properties of the tool materials

\begin{tabular}{llcccccccc}
\multicolumn{2}{c}{ Materials } & $\begin{array}{c}\text { Fibre } \\
\text { Volume } \\
\text { fraction }\end{array}$ & $\begin{array}{c}\text { Poisson's } \\
\text { ratio }\end{array}$ & CTE & $\begin{array}{c}\text { tensile } \\
\text { modulus }\end{array}$ & $\begin{array}{c}\text { Shear } \\
\text { modulus }\end{array}$ & $\begin{array}{c}\text { Ultimate } \\
\text { tensile } \\
\text { strength }\end{array}$ & $\begin{array}{c}\text { Ultimate } \\
\text { compressive } \\
\text { strength }\end{array}$ & $\begin{array}{c}\text { Ultimate } \\
\text { Shear } \\
\text { strength }\end{array}$ \\
\cline { 2 - 9 } & - & - & ${ }^{\circ} \mathrm{C}^{-1}$ & $\mathrm{MPa}$ & $\mathrm{MPa}$ & $\mathrm{MPa}$ & $\mathrm{MPa}$ & $\mathrm{MPa}$ \\
\hline Alepoxy & orthotropic & 0.48 & 0.34 & $32 \times 10^{-6}$ & 6200 & 2300 & 120 & -190 & 140 \\
Copper $^{[1]}$ & orthotropic & - & 0.34 & $17 \times 10^{-6}$ & $110 \times 10^{3}$ & $41 \times 10^{3}$ & 430 & -430 & 170 \\
CFRP & In-plane & 0.58 & 0.451 & $1.9 \times 10^{-6}$ & 8100 & $21 \times 10^{3}$ & 740 & -490 & 53 \\
& Out-plane & 0.58 & 0.219 & $2.3 \times 10^{-6}$ & 35600 & 2800 & 160 & -240 & 50 \\
\hline
\end{tabular}

Table 2 The analytic and numerical analysis results of the cylindrical model

\begin{tabular}{lccc} 
& Max. deformation & Max. strain & Axial \& tangential stresses \\
\cline { 2 - 4 } Analysis methods & $\mathrm{mm}$ & $\mathrm{mm} / \mathrm{mm}$ & $\mathrm{MPa}$ \\
\hline Analytic & $2.96 \times 10^{-3}$ & $5.82 \times 10^{-4}$ & -109.03 to 97.8 \\
Numerical & $3 \times 10^{-3}$ & $5.9 \times 10^{-4}$ & -107.85 to 98.7 \\
Absolute difference percentage & $1.3 \%$ & $1.4 \%$ & $1.3 \%$
\end{tabular}



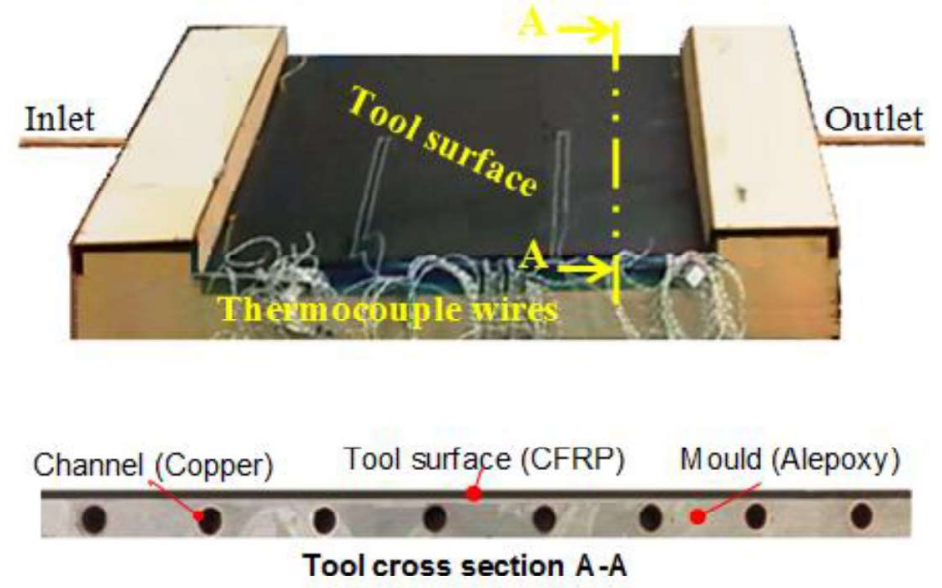

Figure 1 the water-heated tool.

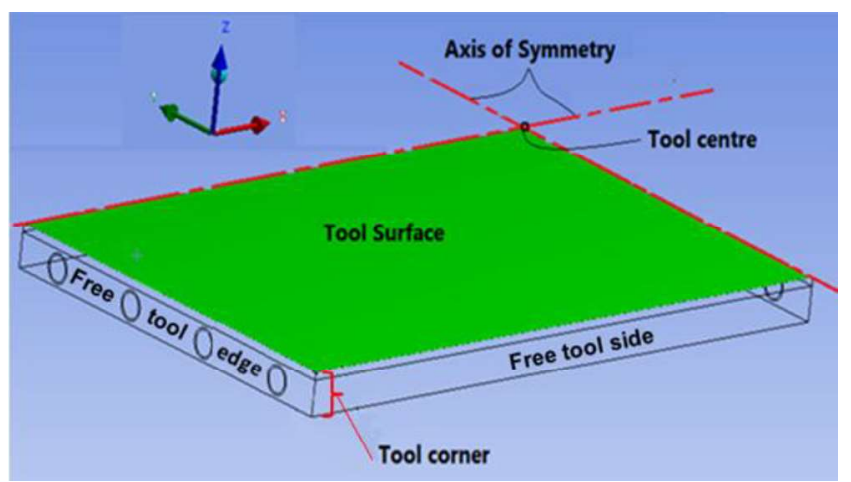

Figure 2 A one-quarter model of the tool

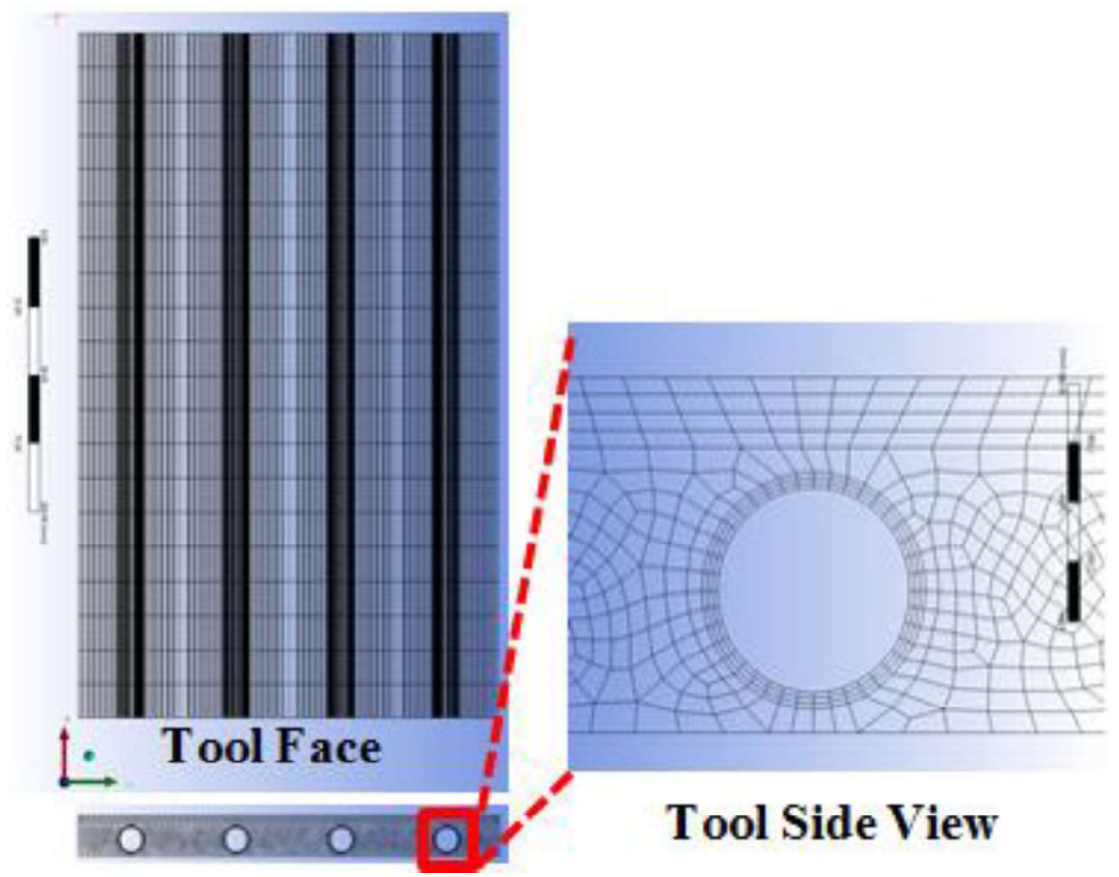

Figure 3 Meshing of the experimental tool model. 


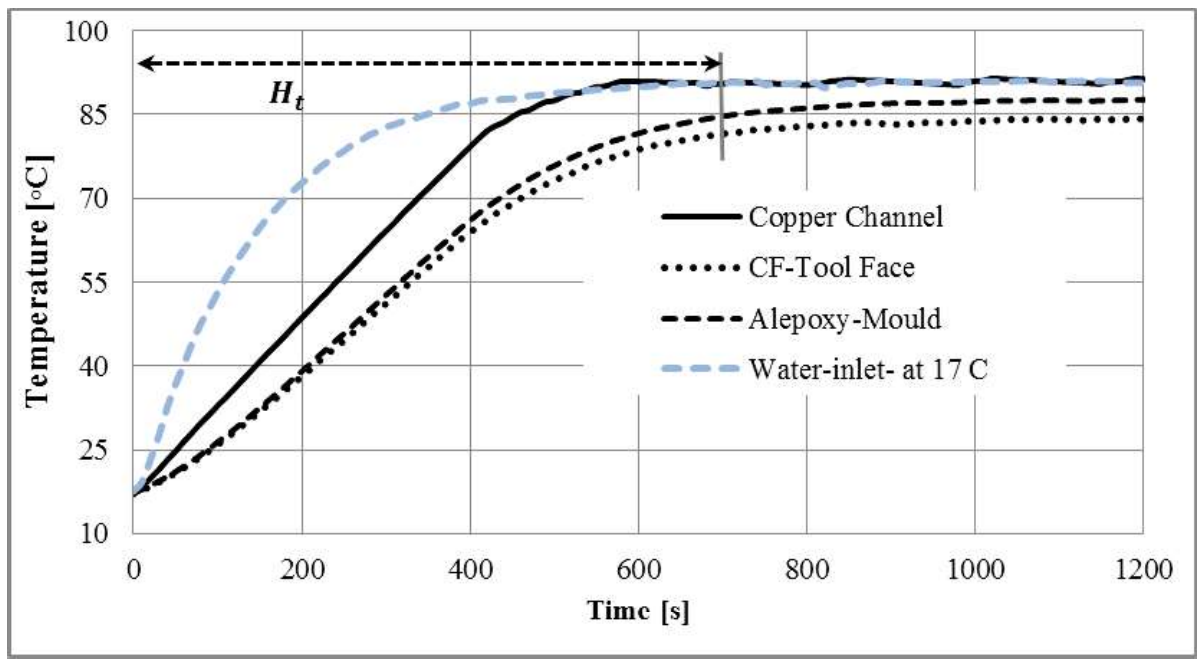

Figure 4 The heating profiles applied to each part of the tool model.

\section{Performing Flextural Test experimentally}

Calculating Flextural Modulus [Eb exp ]

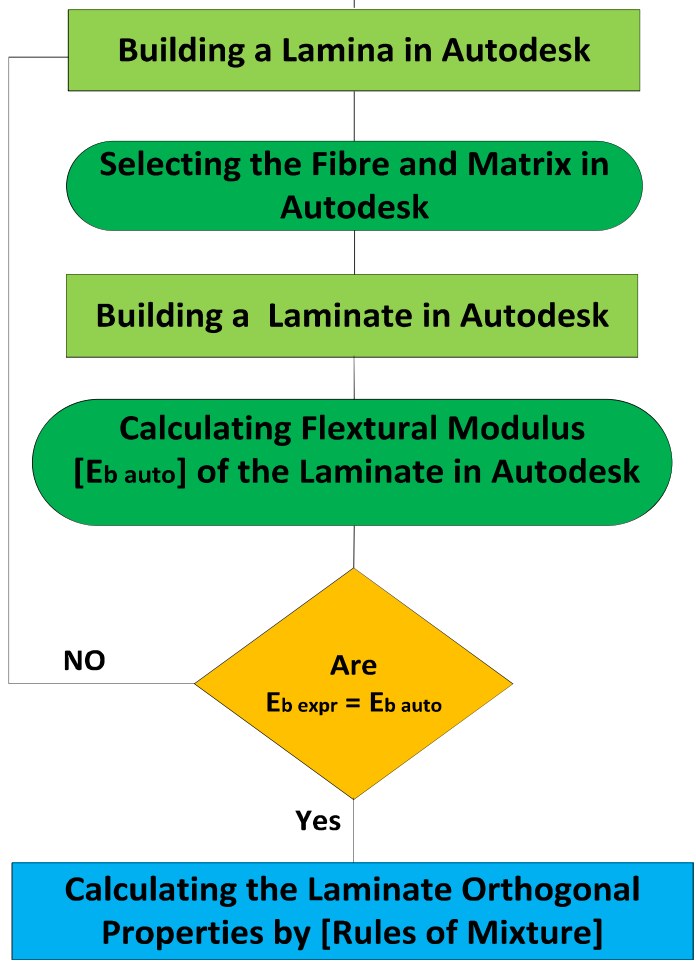

Figure 5 Calculation plan for the mechanical properties of CF laminate. 


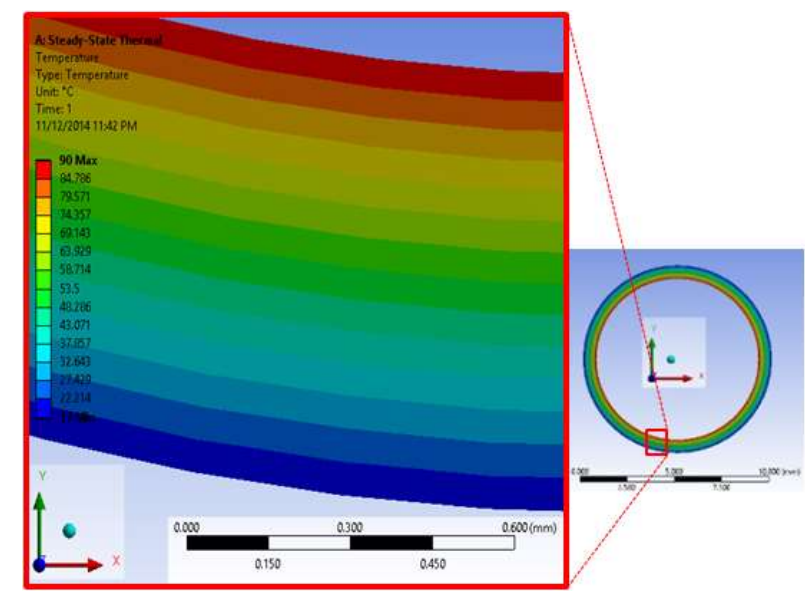

Figure 6 Numerical distribution of temperature throughout the tube thickness. The internal and external faces of the tube were set at $90^{\circ} \mathrm{C}$ and $17^{\circ} \mathrm{C}$, respectively as boundary condition.

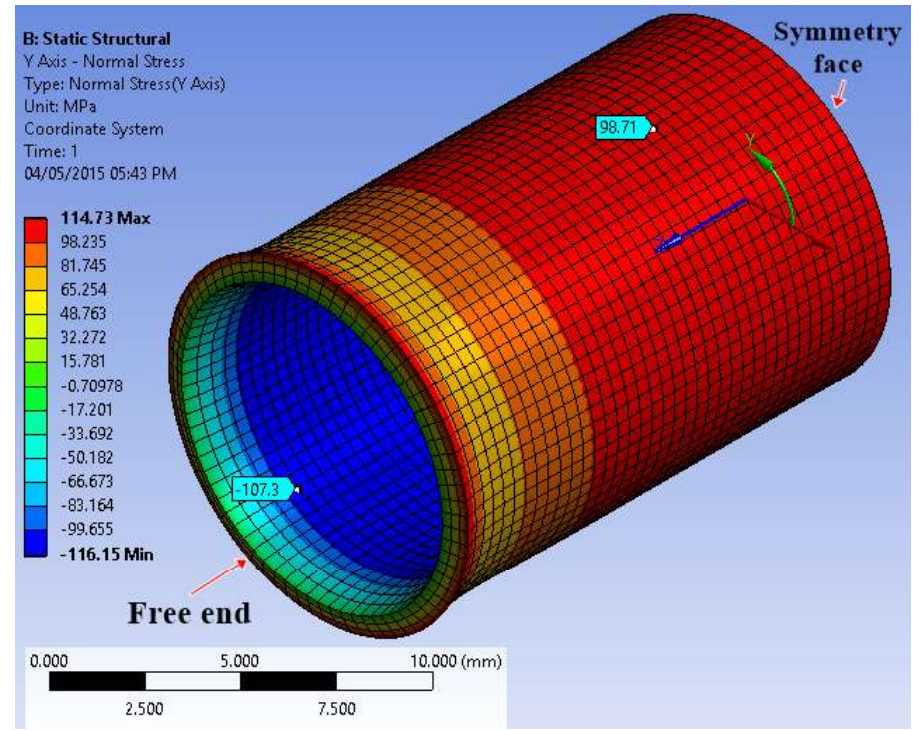

Figure 7 Tangential normal stresses in the cylindrical model

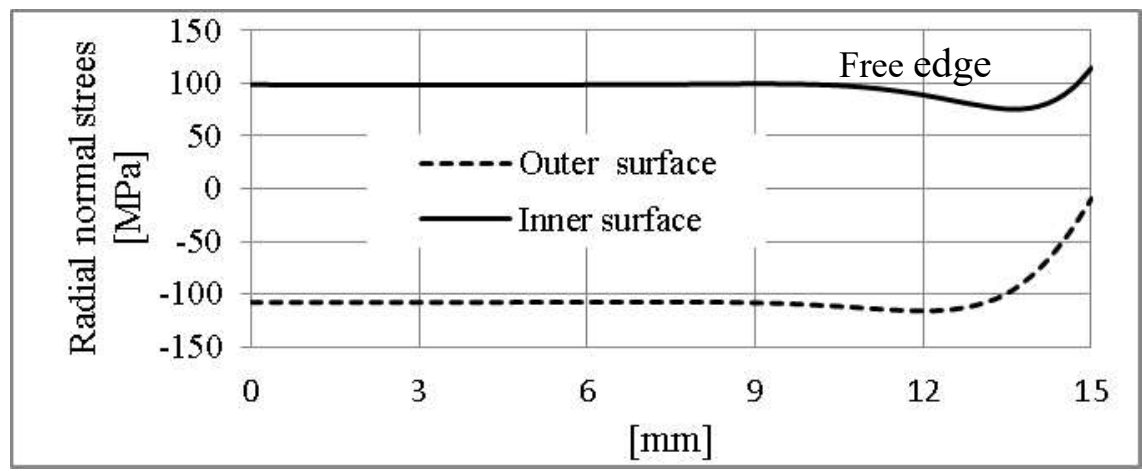

Figure 8 Tangential normal stress along the inner and outer tube surfaces, towards the free end. 


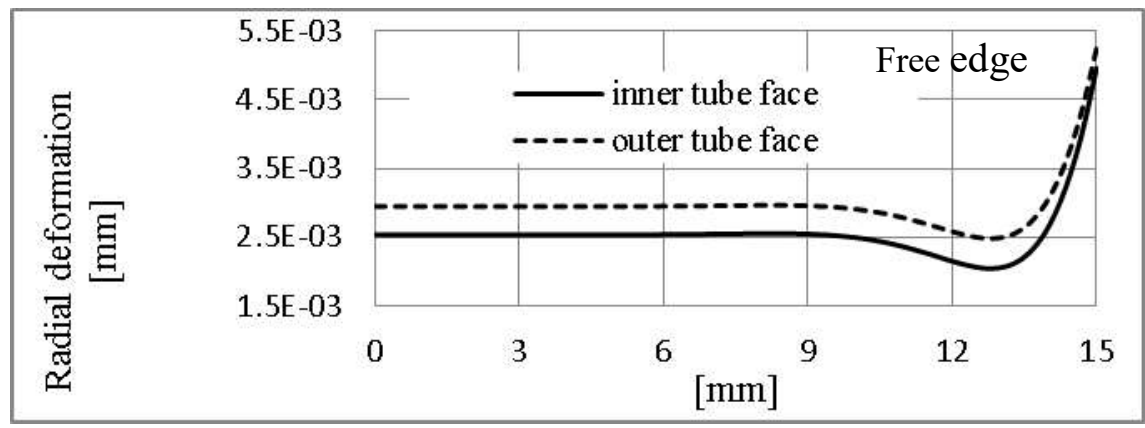

Figure 9 Radial deformation along the length of inner and outer tube surfaces, towards the free end.

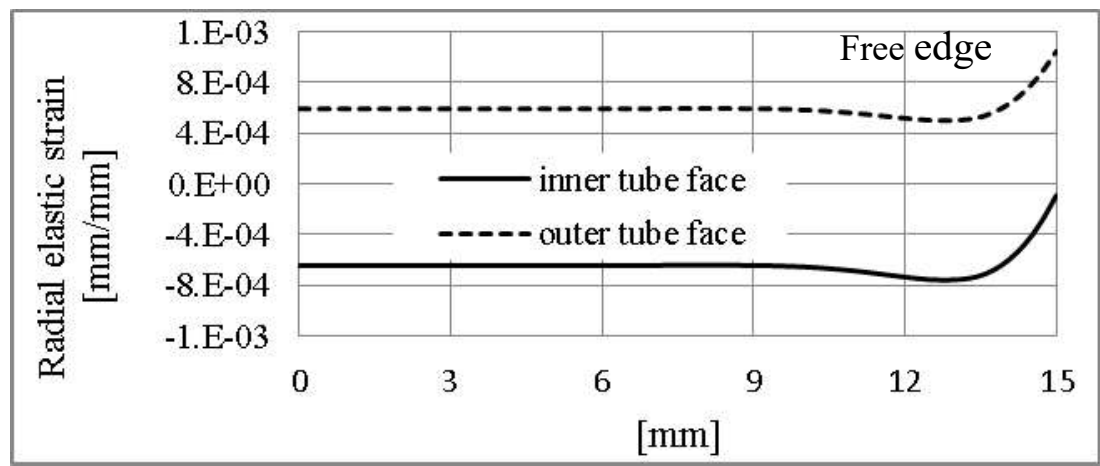

Figure 10 Radial elastic strain along the length of inner and outer tube surfaces, towards the free end.

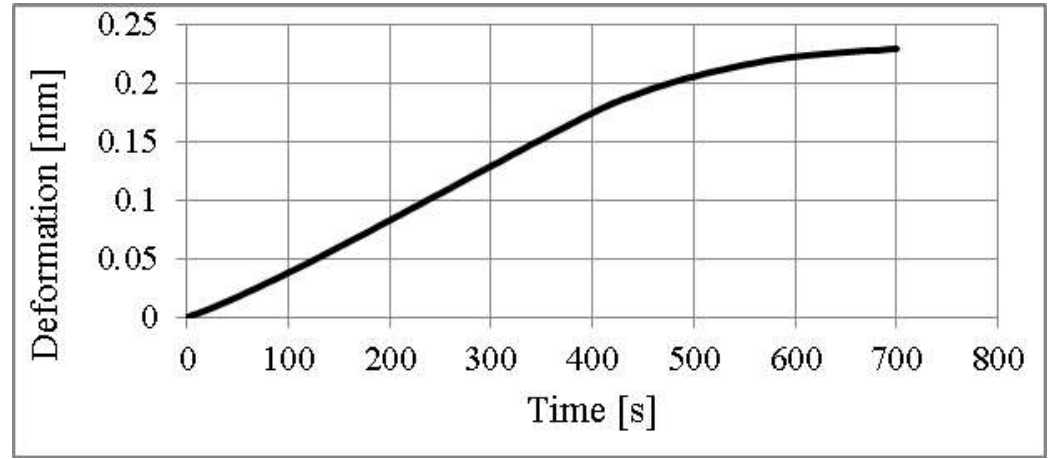

Figure 11 Transient total deformation in the tool. 


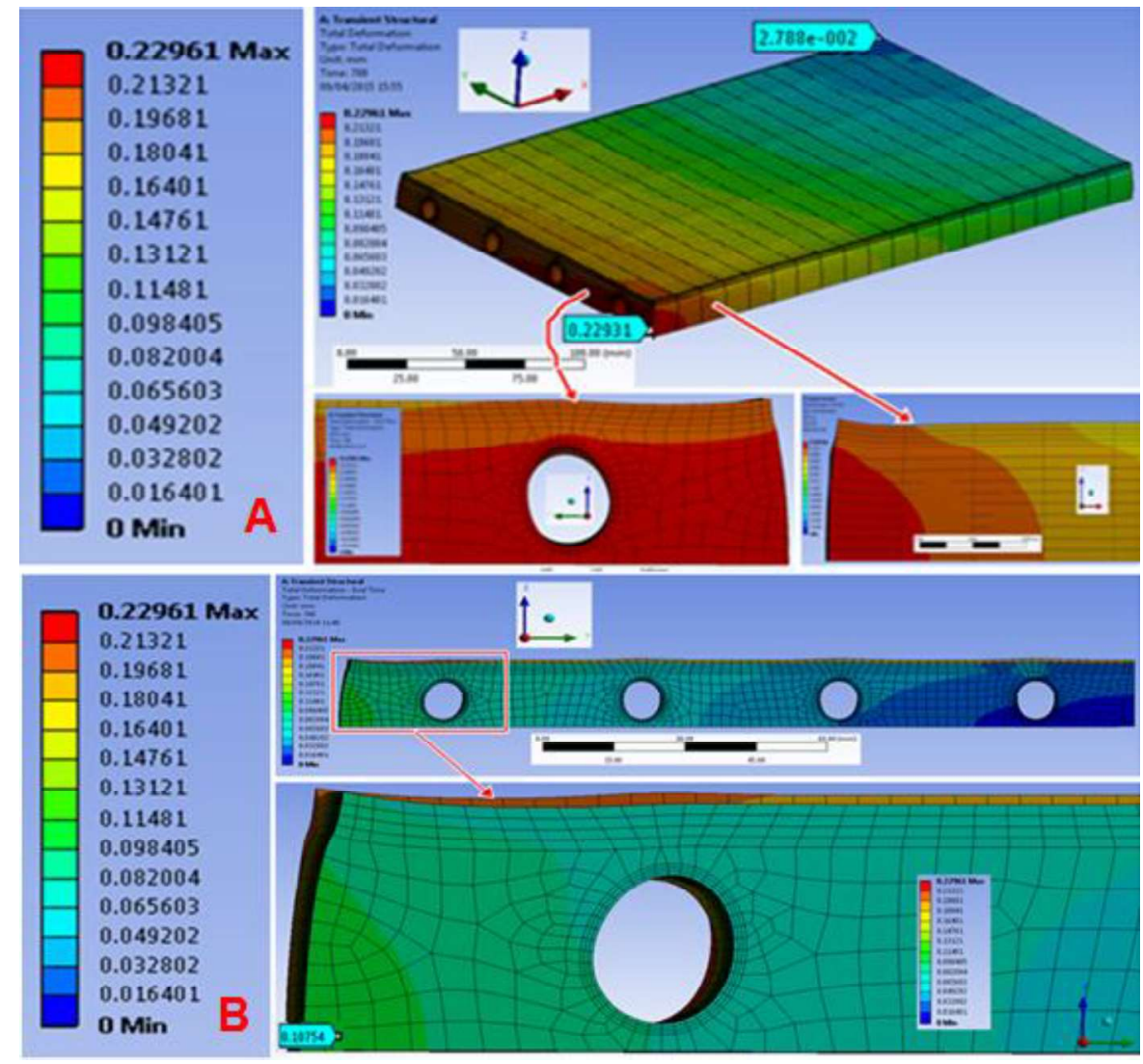

Figure 12 Total deformation in the: A) tool model and its free edge. B) Transverse symmetry side of the tool, $H_{t}=700 \mathrm{~s}$

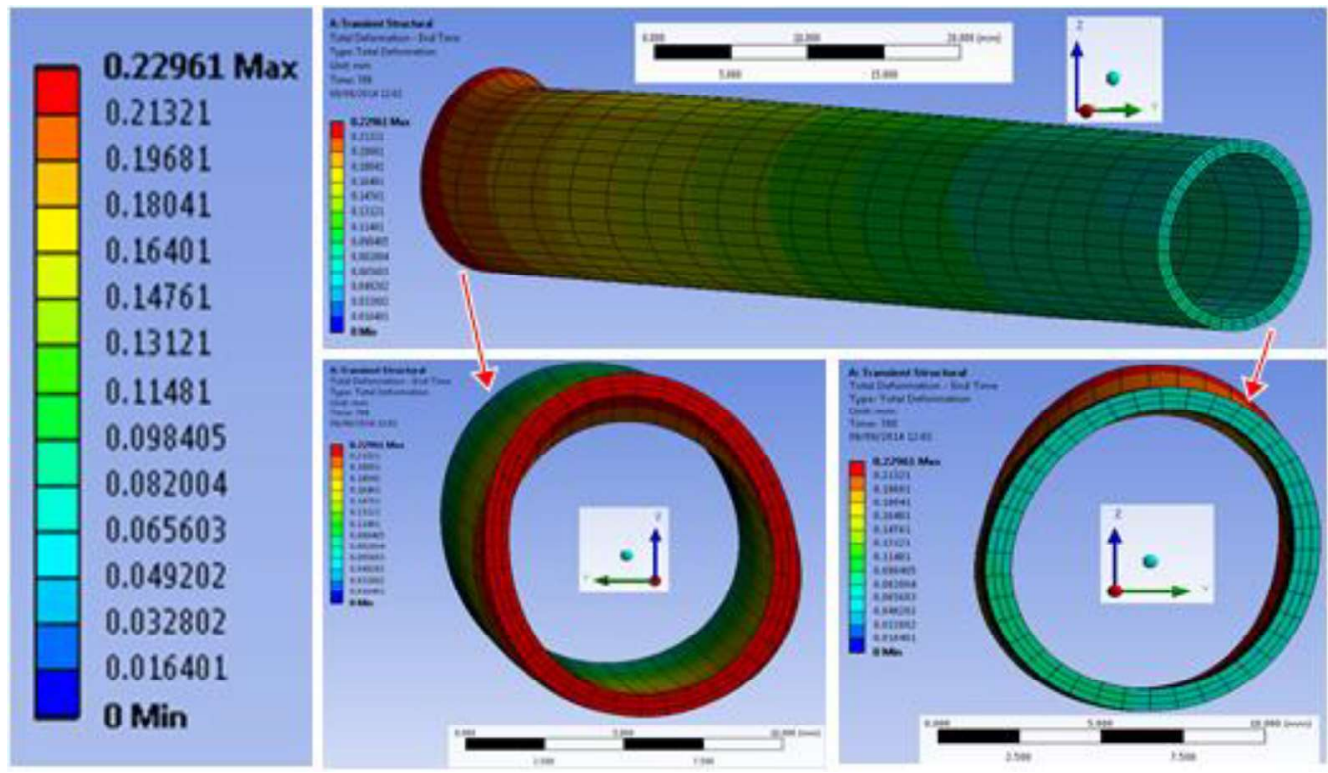

Figure 13 Total deformation in a channel, $H_{t}=700 \mathrm{~s}$ 


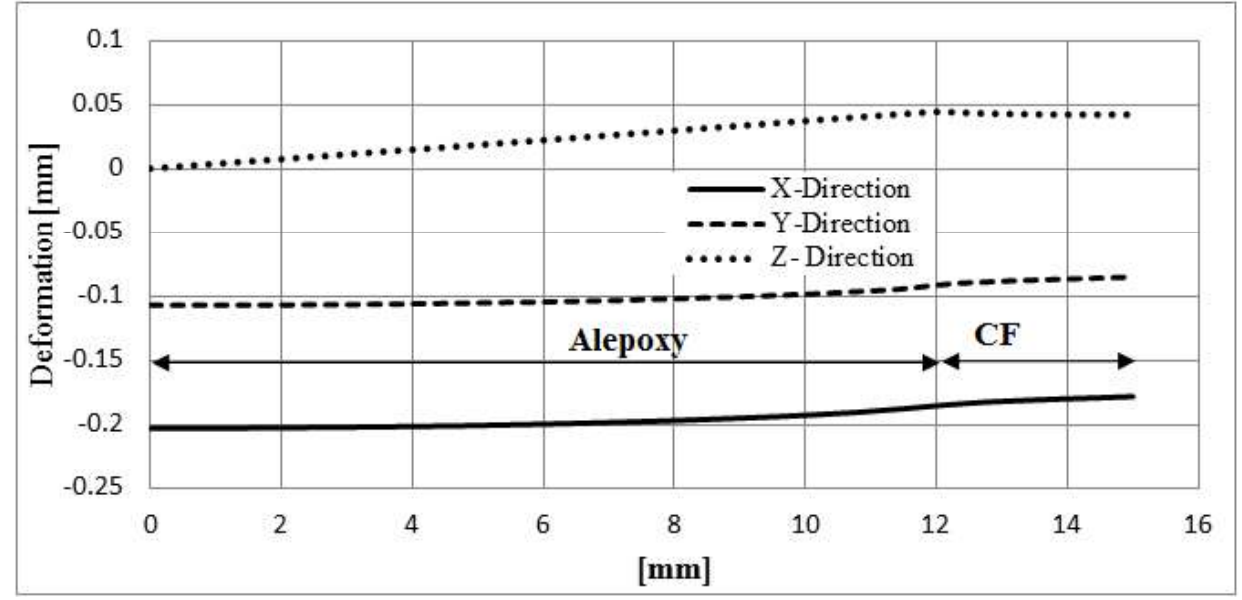

Figure 14 Directional deformations along the tool corners, $H_{t}=700 \mathrm{~s}$

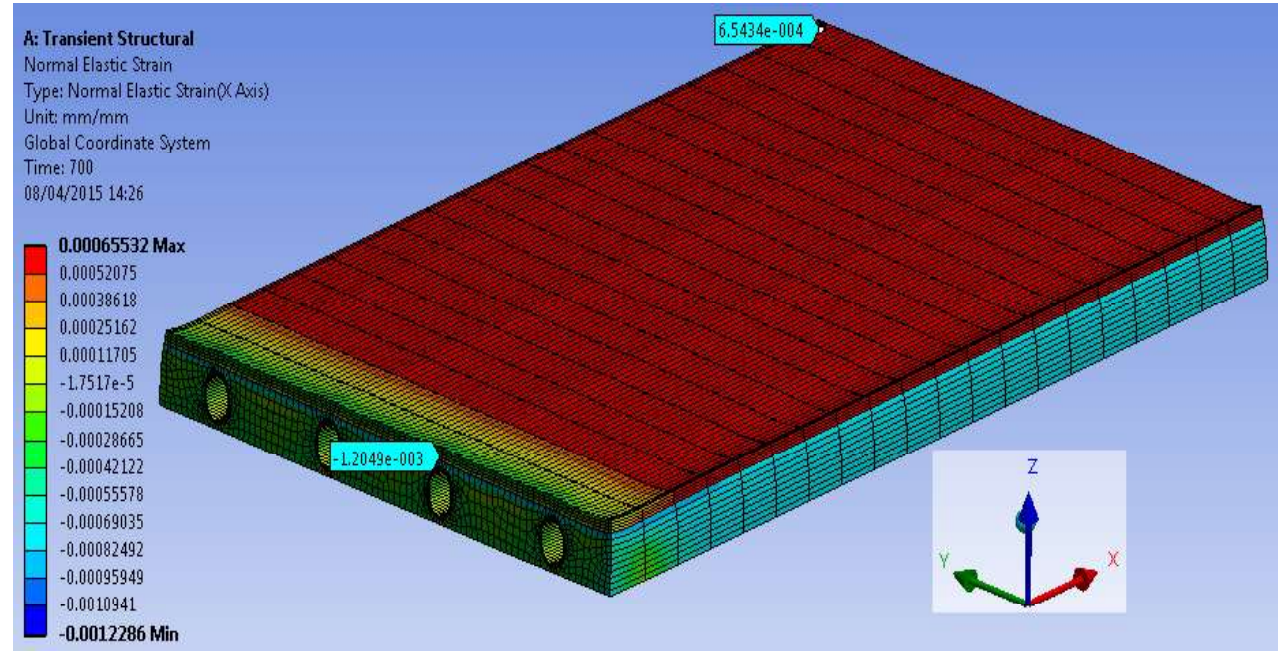

Figure 15 Longitudinal (x-axis) normal elastic strain in the tool, $H_{t}=700 \mathrm{~s}$

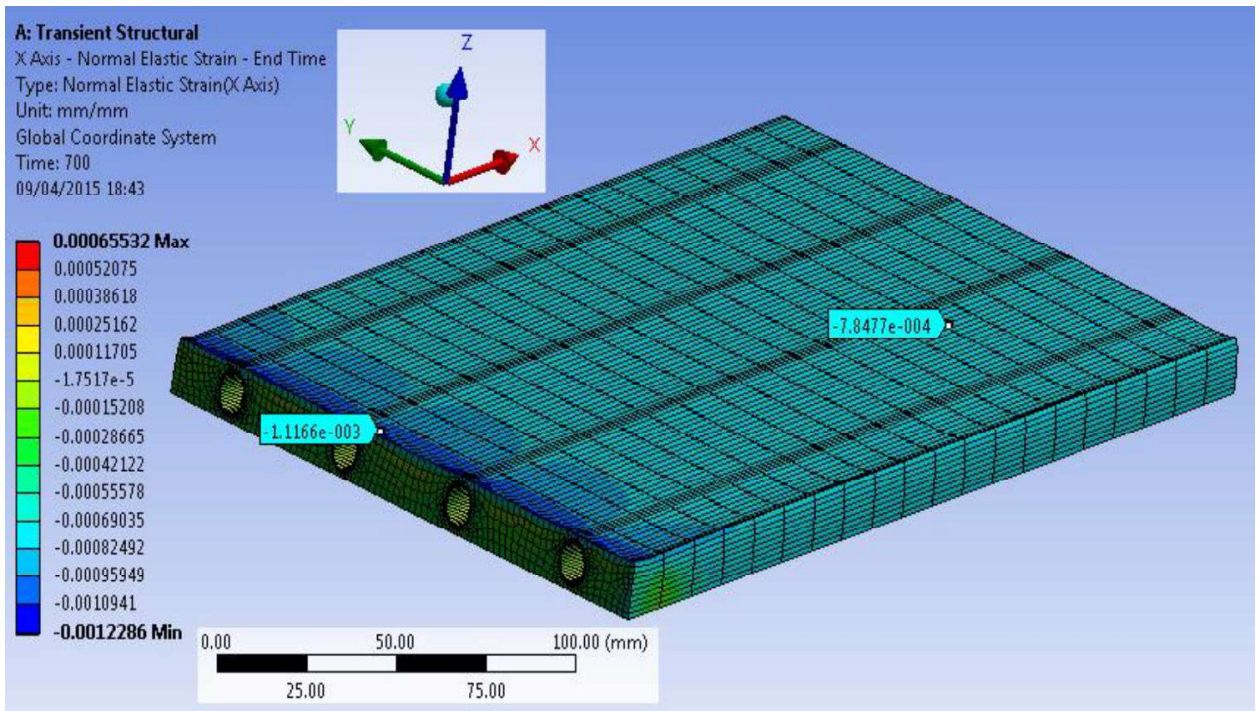


Figure 16 Longitudinal (x-axis) normal elastic strain in the mould, $H_{t}=700 \mathrm{~s}$

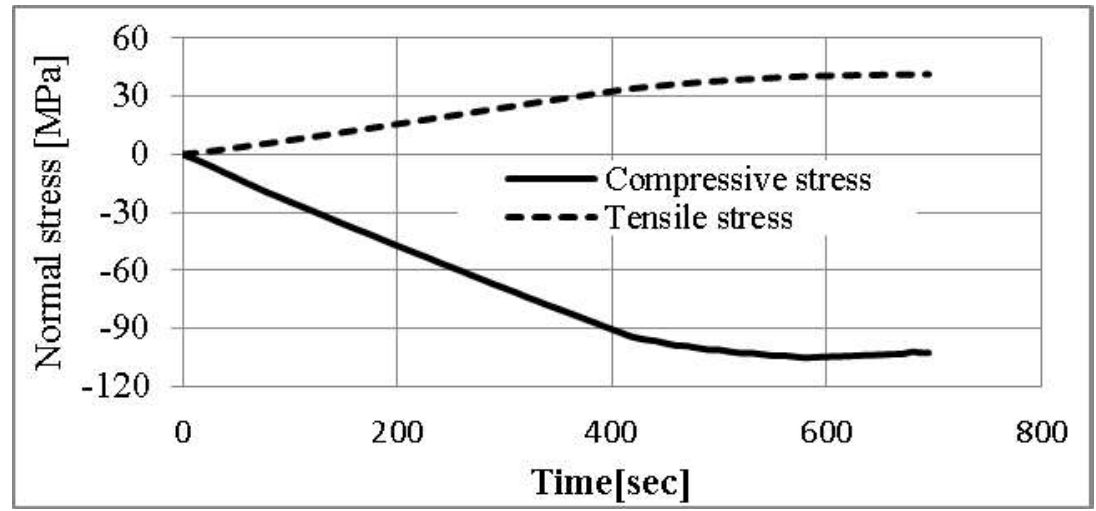

Figure 17 Longitudinal (x-axis) normal stresses in the tool

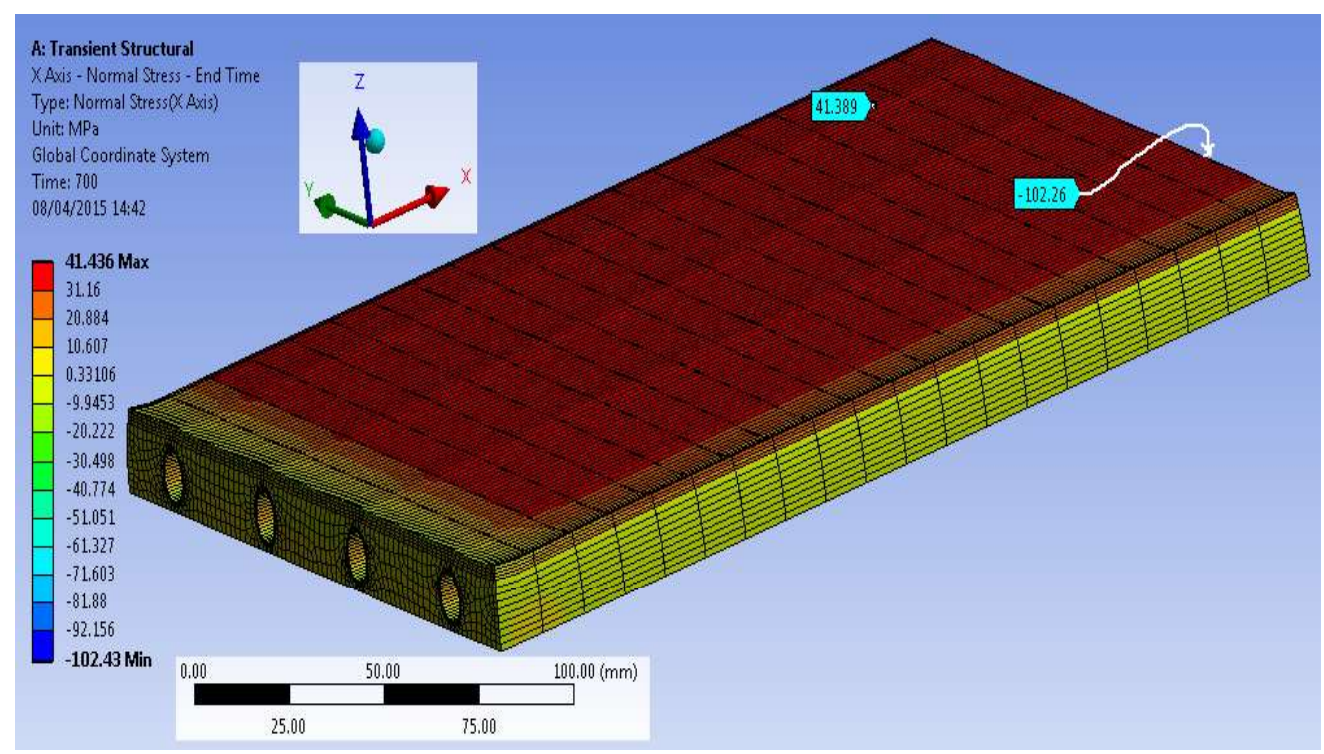

Figure 18 Longitudinal (x-axis) normal stress in the tool, $H_{t}=700 \mathrm{~s}$ 


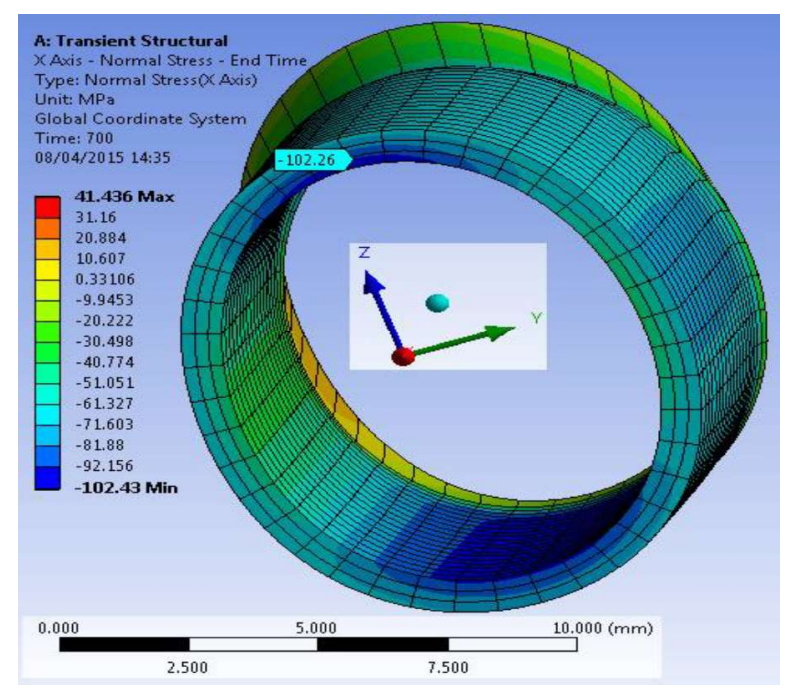

Figure 19 Longitudinal (x-axis) normal stress in a channel, $H_{t}=700 \mathrm{~s}$

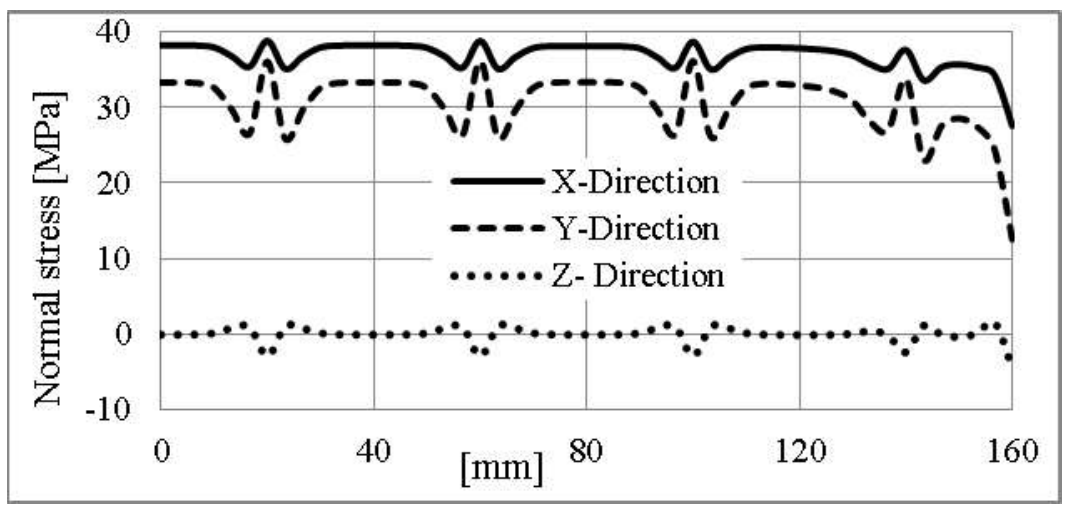

Figure 20 Normal stress along the transverse symmetry side of the tool interface between CFRP and Alepoxy

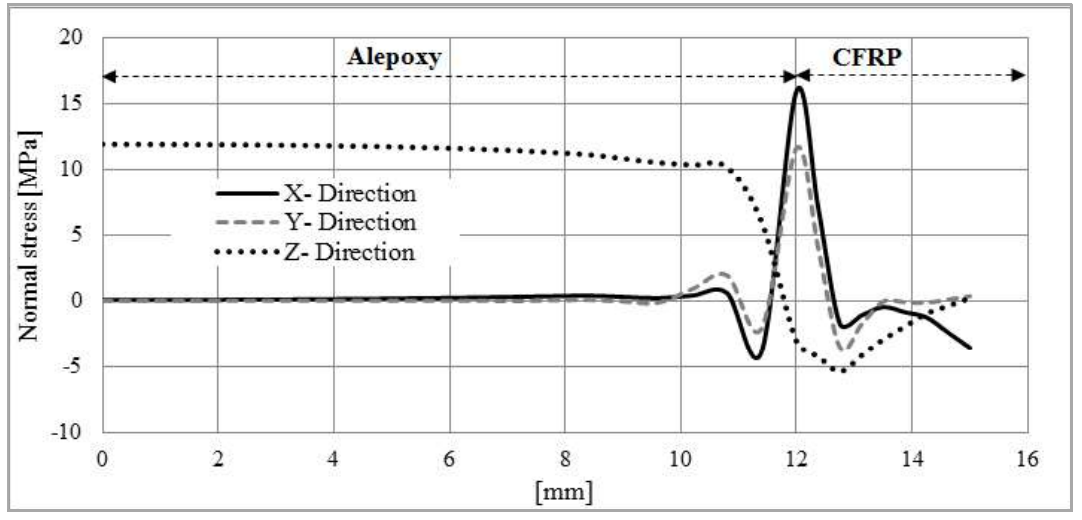

Figure 21 Normal stress along the tool corners

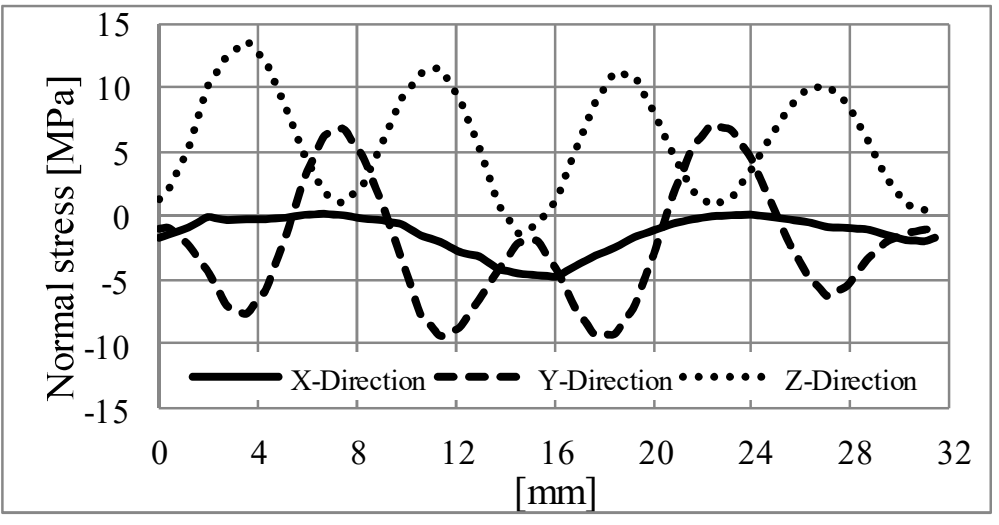


Figure 22 Normal stress along the channel free ends

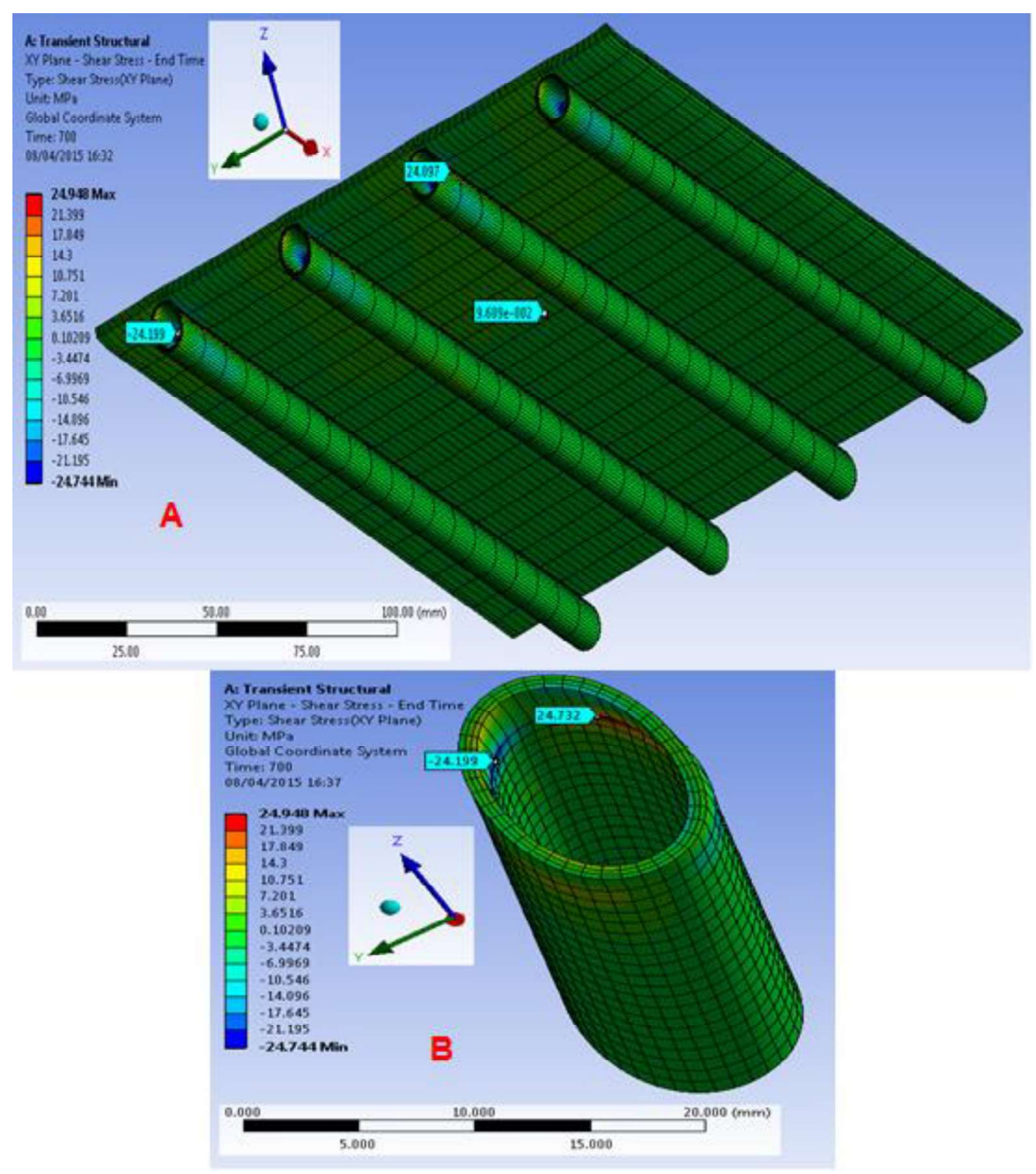

Figure 23 xy-plane shear stresses: A) at the tool interfaces. B) in the channel, $H_{t}=700 \mathrm{~s}$ 


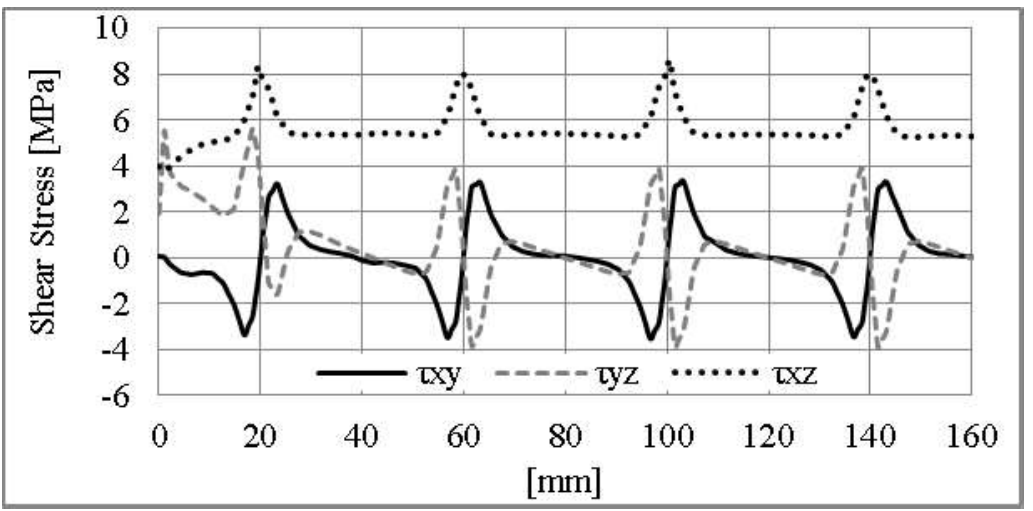

Figure 24 Plane shear stresses along free ends of the Alepoxy and CFRP interface.

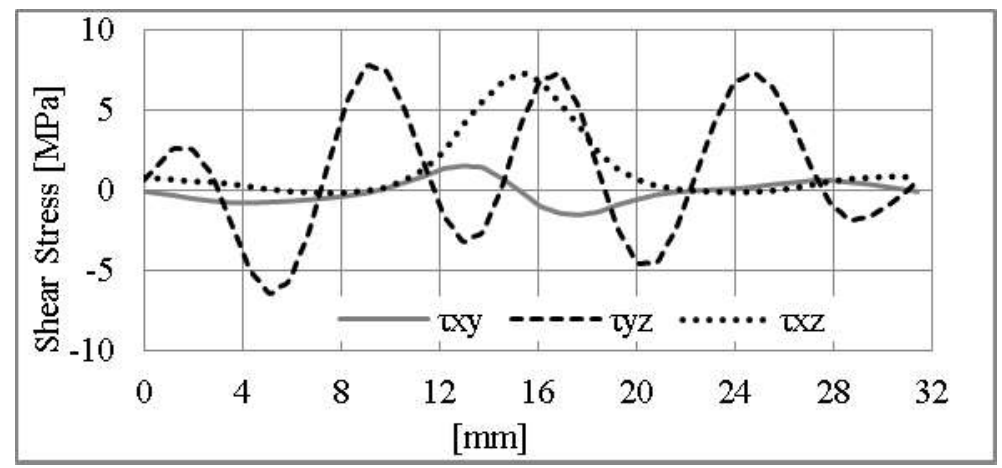

Figure 25 Plane shear stresses along the tube free ends (mould channel interface). 